\title{
Sea level time series and ocean tide analysis from multipath signals at five GPS sites in different parts of the world
}

\author{
Johan S. Löfgren, Rüdiger Haas, Hans-Georg Scherneck
}

Chalmers University of Technology, Department of Earth and Space Sciences, Onsala Space Observatory, SE-439 92 Onsala (Sweden)

\begin{abstract}
We present sea level observations derived from the analysis of Signal-to-Noise Ratio (SNR) data recorded at five coastal GPS sites. These sites are located in different regions around the world, both in the northern and the southern hemisphere, in different multipath environments, from rural coastal areas to busy harbors, and experience different tidal ranges.

The recorded SNR data show periodic variations that originate from multipath, i.e. the interference of direct and reflected signals. The general assumption is that for satellite arcs facing the open sea, the SNR variations are due to reflections off the sea surface. The SNR data recorded from these azimuth intervals were analyzed by spectral analysis with two approaches, a simple analysis approach assuming static sea level during a satellite arc, and an extended analysis approach that involves a time dependent sea level during a satellite arc.

The GPS-derived sea level results were compared to sea level records from co-located traditional tide gauges, both in the time and frequency domain. The sea level time series are highly correlated with correlation coefficients on the order of $0.89-0.99$. The root-mean-square (RMS) differences are on the order of $6.2 \mathrm{~cm}$ for stations with low tidal range (up to $165 \mathrm{~cm}$ ) and $43 \mathrm{~cm}$ for stations with high tidal range (up to $772 \mathrm{~cm}$ ). The relative accuracy, defined as the ratio of RMS and tidal range, is between $2.4 \%$ and $10.2 \%$ for all stations.

The results based on the extended SNR-analysis approach agree better with the tide gauge results, than the results of the simple approach, for the stations with high tidal range. For the station with the highest tidal range $(772 \mathrm{~cm})$, the RMS is reduced by $47 \%$ when using the extended approach. Furthermore, the results also indicate that the simple approach assuming a static sea level can be used for stations with a tidal range of up to about $270 \mathrm{~cm}$, without performing significantly worse than the extended analysis approach.

Tidal amplitudes and phases were derived by harmonic analyses of the sea level records. Again, a high level of agreement is observed between the tide gauge and GPS-results. The results based on the extended SNR-analysis approach show a higher degree of agreement with the tide gauge results, than the results of the simple approach for stations with large tidal range. Spectral analysis of the residuals after the harmonic analysis reveals remaining signal power at multiples of the draconitic day. This indicates that the observed SNR data are to some level disturbed by additional multipath signals, in particular for GPS sites that are located in harbors.
\end{abstract}

Keywords: GPS, sea level, signal-to-noise ratio, multipath, ocean tide analysis, reflected signals, tide gauge

\section{Introduction}

The observation of sea level and its changes are of major interest for the geosciences community, since it provides important constraints for global climate modeling. Sea level has been observed primarily with tide gauges during the last centuries $(I O C, 2006)$. For the last 25 years, satellite altimetry has been the dominating technique. However, the comparison of altimeter measurements with tide gauge records has proven to be important to correct instrumental biases in the altimetry data Mitchum (1994); Chambers et al. (1998); Mitchum (2000). Tide gauges are, however, affected by both sea level and land surface changes, since the measurements are related to a benchmark on the land where they are established. This makes it difficult to use traditional tide gauges for sea level studies in tectonically active areas and for applications related to changes in the global ocean volume, e.g., the global sea level budget (Bindoff et al., 2007). These applications need absolute measurements of sea level, i.e., measurements with respect to a terrestrial reference frame (Church et al., 2011).

Global Navigation Satellite Systems (GNSS) can be used to measure the land surface changes, e.g., Lidberg et al. (2010); Scherneck et al. (2010), and the combination of GNSS and tide gauges observations allows to derive sea level change with respect to the International Terrestrial Reference Frame (ITRF), e.g., Wöppelmann et al. (2009); Schöne et al. (2009).

Furthermore, Martin-Neira (1993) introduced the application of reflected GNSS signals for remote sensing of the oceans. Thereafter, several studies of ocean and lake level measurements with Global Positioning System (GPS) data, were carried 
out, using different land-based setups, e.g., (Anderson, 2000; Martin-Neira et al., 2002; Belmonte Rivas and Martin-Neira, 2006; Caparrini et al., 2007; Löfgren et al., 2011a,b; Larson et al., 2013a,b).

The study by Anderson (2000) is particularly interesting, since it was the first time that the interference pattern in the recorded Signal-to-Noise Ratio (SNR), originating from the ocean reflected signal interfering with the direct satellite signal, was related to measurements of sea level height. In a later study by Larson et al. (2013a) a GPS station with a zenith-looking antenna, installed primarily for geodetic measurements, was used to sucessfully measuring sea level of the nearby ocean during three months. The technique was extended by Larson et al. (2013b) to improve the performance for sites with large tidal variations $(>7 \mathrm{~m})$.

In the present study, we apply the SNR technique to datasets of five different coastal GPS sites around the world. These GPS sites are chosen for their different locations and conditions, i.e., different latitudes (from $57.5^{\circ} \mathrm{N}$ to $63.3^{\circ} \mathrm{S}$ ), different surroundings (from an antenna with open sea water in several directions to an antenna on a pier in a harbor), different tidal ranges (from $1.5 \mathrm{~m}$ to $7.5 \mathrm{~m}$ ), and different tidal components (sea level driven by tides and sea level primarily driven by meteorological forcing). The aim is to evaluate the SNR technique and investigate its performance and identify its restrictions. For the evaluation we use sea level from co-located tide gauges and compare both the direct sea level and the results after a harmonic analysis.

Sec. 2 is a general overview of the SNR technique, describing how to utilize the sea surface reflections for measuring sea level. The GPS sites used in this study and the co-located traditional tide gauges are presented in Sec. 3. The data analysis is described in Sec. 4 and the resulting GPS-derived sea level time series are presented in Sec. 5 together with a comparison to the tide gauge sea level. A harmonic analysis is performed on the sea level time series and the results are presented in Sec. 6. This is followed by a discussion in Sec. 7 and finally, the conclusions in Sec. 8.

\section{Multipath, SNR observations, and sea level}

GNSS antennas are designed to be sensitive to the direct satellite signals and to suppress the unwanted reflected signals from the surroundings, i.e., the antenna gain pattern has higher values for the upper hemisphere than for the lower hemisphere, see e.g., Bedford et al. (2009). However, a portion of the reflected signals reaches the antenna, interfering with the direct signals, and affecting the GNSS observables recorded by the receiver, see Fig. 1. This is known as multipath and is one of the major error sources in high-accuracy positioning, e.g., for measuring tectonic motion and crustal deformation, and there are numerous studies on how to mitigate the effect, e.g., Georgiadou and Kleusberg (1988); Elósegui et al. (1995); Hannah (2001); Park et al. (2004); Bilich et al. (2008).

During recent years, several studies have been using the traditionally unwanted multipath signals for remote sensing of the environment close to the antenna, e.g., for sensing soil moisture (Larson et al., 2008), snow depth (Larson et al., 2009),

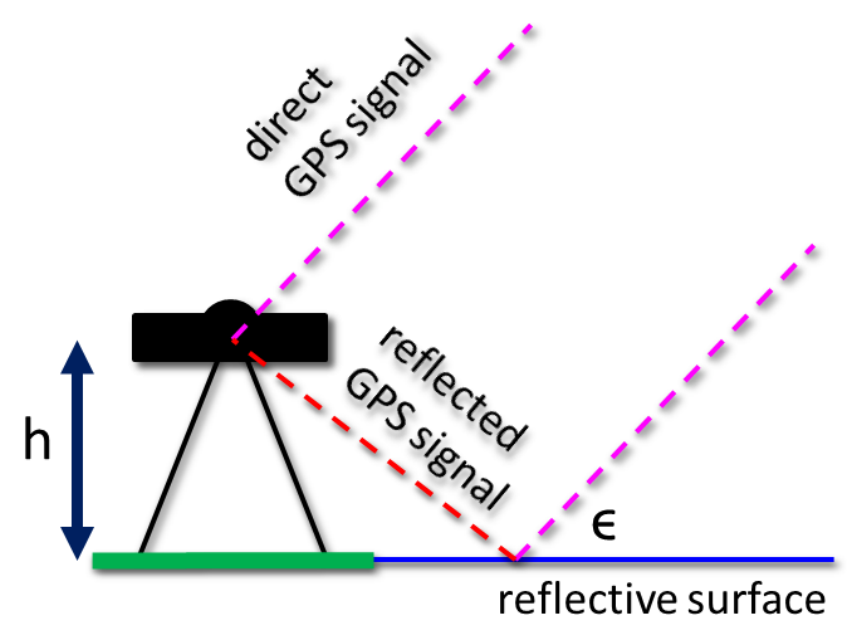

Figure 1: Schematic drawing of a GPS antenna affected by multipath from the ocean. The satellite elevation angle is denotet by $\epsilon$ and the reflector height, the distance between the antenna phase centre and the reflecting surface, is denoted by $h$.

locating reflecting objects (Benton and Mitchell, 2011), and sea level (Larson et al., 2013a,b). In these studies the SNR data recorded by the GPS receivers have been utilized to determine the distance between the receiving antenna and the assumed horizontal reflecting surface through analysis of the SNR interference pattern. This SNR pattern originates from the phase difference between the direct and the multipath signal, which changes when the satellite moves across the sky. Examples of SNR patterns are presented in Fig. 2. In order to isolate the multipath contribution of the SNR observation, i.e., the oscillation of the SNR data, the direct signal part, corresponding to the overall increasing arc in Fig. 2, needs to be removed. This can be done either by removing a model for the direct signal including atmospheric attenuation and the antenna gain pattern, or by fitting and removing a polynomial, see e.g., Bilich et al. (2008); Larson et al. (2009, 2013a). Before this is done for each rising and setting satellite arc, the SNR data is converted to linear scale in watt per watt, assuming a $1 \mathrm{~Hz}$ bandwidth. After removing the overall arc from the SNR data, the resulting multipath contribution of the SNR, here designated detrended SNR $(d S N R)$, can be described by

$$
d S N R=A \cos (\theta+\varphi)=A \cos \left(\frac{4 \pi h}{\lambda} \sin \epsilon+\varphi\right)
$$

where $A$ is the amplitude (depending on the properties of the reflecting surface and the antenna gain pattern), $\theta$ is the phase of the dSNR, and $\varphi$ is a phase offset. The phase of the dSNR depends on $h$, which is the distance between the antenna phase centre and the reflecting surface (also called reflector height), $\lambda$, which is the GPS carrier wavelength, and $\epsilon$, which is the satellite elevation.

Assuming that the reflector height is not time dependent and a horizontal reflector, the phase $(\theta)$ of the dSNR is constant with 


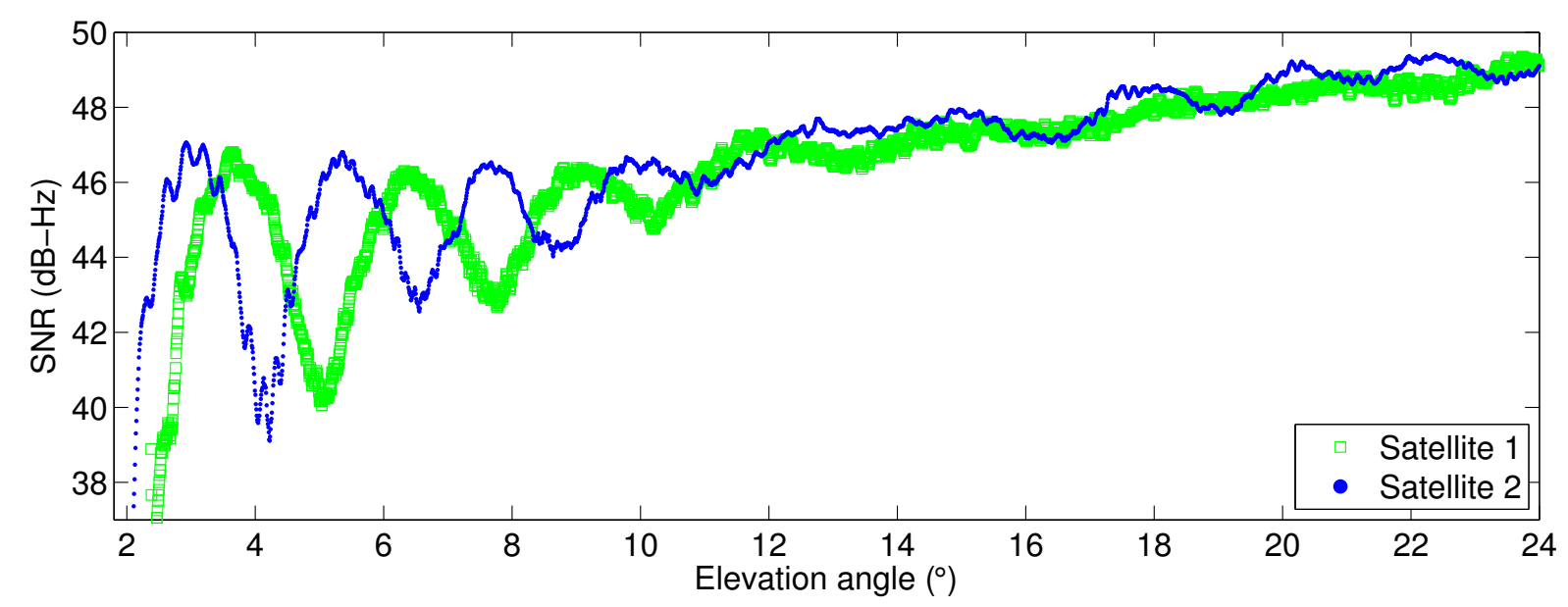

Figure 2: Observations of signal-to-noise-ratio (SNR) as a function of satellite elevation angle for two satellites at two different times during the day (satellite 1 is observed in the evening and satellite 2 is observed in the morning). The receiving antenna is located close to the ocean and thus receiving multipath signals from that direction that interfere with the direct signals and creating oscillations in the SNR. SNR data are typically reported as carrier-to-noise-density ratio with the unit dB-Hz (Joseph, 2010).

respect to sine of satellite elevation angle according to

$$
\frac{d \theta}{d \sin \epsilon}=\frac{4 \pi h}{\lambda}
$$

This means that, under the previous assumptions, the multipath modulation frequency (measured in cycles per sine of elevation angle) is constant, $2 h / \lambda$. As an example, Fig. 3 depicts dSNR as a function of sine of elevation angle for two satellite observations, clearly showing a constant multipath frequency for each arc. Another point that can be made from Eq. 1 and Eq. 2 is that a high reflector height corresponds to a high multipath frequency and vice versa (compare to Fig. 3). Since the reflector height for a GPS station next to the ocean is directly proportional to the sea surface height, this means that a high multipath frequency (a large distance between antenna and the sea surface) corresponds to a low sea level, whereas a low multipath frequency (a short distance between antenna and the sea surface) corresponds to a high sea level.

The dominant multipath frequency (or reflector height) can be derived from the dSNR data by a spectral analysis. In recent studies, e.g., Larson et al. (2009, 2013a), the Lomb Scargle Periodogram (LSP) has been used since it can handle unevenly spaced samples, which is difficult for, e.g., the Fast Fourier analysis. The recorded SNR data are typically evenly sampled in time, but not as a function of sine of elevation. As an example, Fig. 4 depicts the results of analyzing the dSNR data from Fig. 3 with LSP.

An assumption made when detecting the peak of the spectral amplitude (or the reflector height peak) is that the LSP spectrum, or at least the peak of the LSP spectrum, only consists of one single frequency. Obviously, this does not have to be true. First of all, the sea surface is usually not perfectly flat. Second, the observed SNR data are affected by multipath from multiple reflectors located in the surroundings of the GPS antenna. With a satellite azimuth and elevation mask it is possible to select observations from directions where the sea surface is expected to be the only reflector, but there can be additional sources of reflection from, e.g., the ground next to the antenna or the antenna installation. If these additional reflections are close in multipath frequency to the reflection from the sea surface, they will overlap in the LSP spectrum, which could distort the peak and introduce an error in the retrieved sea level.

When this GPS tide gauge technique was applied to a coastal site with high tidal variations ( $>7 \mathrm{~m}$ ), it was seen that the model, assuming a constant reflector height or sea level throughout the satellite arc, was not sufficient (Larson et al., 2013b). This resulted in differences between sea level solutions from rising and setting satellite arcs. A correction was suggested by Larson et al. (2013b) derived from using a time dependent reflector height, see also Nievinski (2013) for further information. Using the derivative of the dSNR phase, as in Eq. 2, but assuming that the reflector height is time dependent, results in

$$
\begin{array}{r}
\frac{\partial \theta}{\partial \sin \epsilon}=\frac{\partial \theta}{\partial t} \frac{\partial t}{\partial \sin \epsilon}=\left(\frac{4 \pi \dot{h}}{\lambda} \sin \epsilon+\frac{4 \pi h}{\lambda} \cos \epsilon \dot{\epsilon}\right) \frac{1}{\cos \epsilon \dot{\epsilon}}= \\
\frac{4 \pi h}{\lambda} \frac{\tan \epsilon}{\dot{\epsilon}}+\frac{4 \pi h}{\lambda}
\end{array}
$$

where $\dot{h}$ and $\dot{\epsilon}$ are the time derivative of the reflector height and the satellite elevation angle, respectively. Comparing Eq. 3 with Eq. 2, it is clear that the second term on the right-hand side of Eq. 3 is the same as for the case of a constant reflector height described in Eq. 2 earlier. The first term on the right-hand side of Eq. 3 can therefore be seen as a correction term, including the height-rate, to the standard solution in Eq. 2. This means that after SNR-analysis using the assumption of a reflector that is non-moving during the satellite observation, the first term on the right-hand side of Eq. 3 can be removed from the results to create the solution which is based on the assumption of a time dependent reflector. One difficulty with this correction term is 


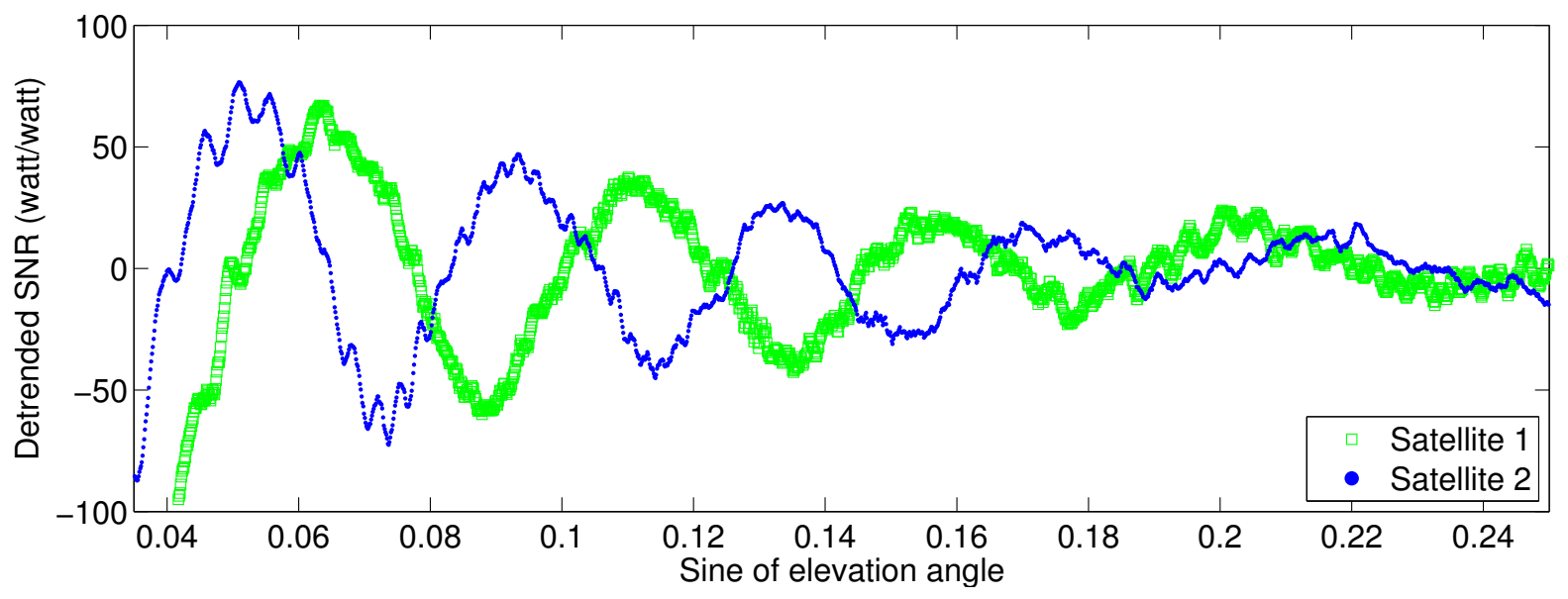

Figure 3: Detrended SNR (dSNR) as a function of sine of elevation for the same satellite arcs as in Fig. 2. Assuming a constant reflector height and a horizontal reflector during the satellite arc, the multipath frequency is constant with respect to sine of satellite elevation angle. The dSNR for satellite 1 (observed in the evening) has a lower multipath frequency than the dSNR for satellite 2 (observed in the morning). This means that the reflector is closer to the antenna during the observation from satellite 1 than during the observation from satellite 2. Converting SNR or dSNR to linear scale results in the unit watt per watt (Joseph, 2010).

of course that in order to accurately determine the unknown parameter (the reflector height), there needs to be prior knowledge of the time derivative of the unknown parameter. This means that the correction either requires a sufficient model or another observation of the reflector height, e.g., from the standard solutions (if it is accurate enough) or from a nearby tide gauge. The latter is of course not acceptable if the GPS tide gauge should be used as an independent technique.

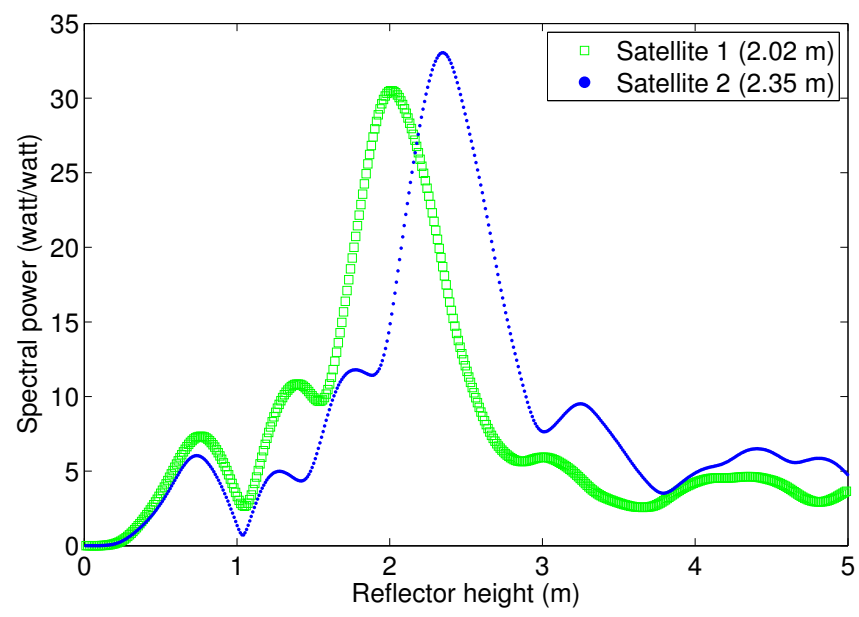

Figure 4: Results after analysis using Lomb Scargle Periodogram of two satellite arcs of detrended SNR as a function of sine of elevation (data are from Fig. 3). Results from satellite 1 (observed in the evening) show a larger reflector height than for satellite 2 (observed in the morning), which corresponds to a lower sea surface during the observation of satellite 1 than for satellite 2 .

\section{Coastal GPS sites}

The goal of this article is to evaluate the potential of the SNR technique for measuring sea level, studying different conditions in terms of, e.g., surrounding environment and tidal range. The main constraint in finding suitable data was to find GPS sites at the coast, close enough to the ocean to receive multipath signals from the water surface. Since the multipath effect on the recorded SNR is most apparent for observations from satellites with low elevations (see Sec. 2), the GPS antenna does not have to be directly on the coastline or in the water to receive multipath signals from the ocean. As long as the antenna has an unobstructed view of the ocean surface, it will be affected by multipath signals. The possible locations of the GPS antenna for this purpose is of course also a function of antenna height over the ocean surface, e.g., an antenna on a higher pillar (long vertical distance between the antenna and the reflecting surface) can be placed further inland, and still be affected by multipath from the ocean, than an antenna on a lower pillar (short vertical distance to the reflecting surface).

Other factors to consider are the sampling rate and the SNR resolution of the receiver. The sampling rate needed for sufficient sampling of the SNR oscillations can be seen as a function of the antenna height over the ocean surface, e.g., an antenna high over the reflecting surface results in SNR oscillations with a higher frequency than for an antenna closer to the reflecting surface, see Elósegui et al. (1995). In practice, this means that the receiver connected to an antenna located vertically high over the ocean surface (high reflector height) needs to have a higher sampling rate in order to resolve the SNR oscillations than the receiver connected to an antenna located vertically closer to the ocean surface (low reflector height); compare with Fig. 3 where a high reflector height corresponds to low sea level and a low reflector height corresponds to high sea level. 


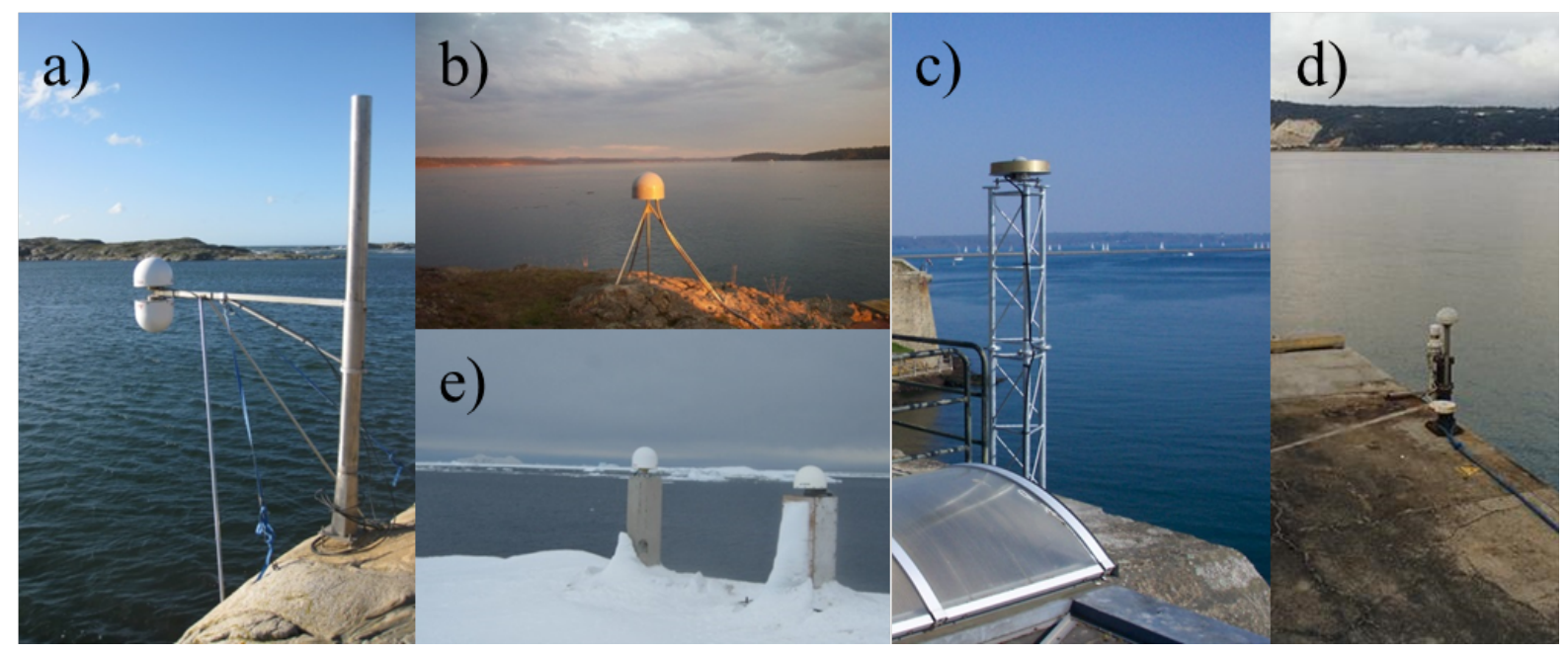

Figure 5: The GPS stations used in this study are from different parts of the world: GTGU in Onsala, Sweden (a); SC02 in Friday Harbor, USA (b); BRST in Brest, France (c); BUR2 in Burnie, Australia (d); OHI3 (left) in O’Higgins, Antarctica (e). Photographs are originally from (a) Johan Löfgren, Chalmers University of Technology, (b) UNAVCO (www.unavco.org), (c) IGS (www.igs.org), (d) Christopher Watson, University of Tasmania, (e) Ruslan Artemenko, Deutsches Zentrum für Luft- und Raumfahrt (DLR).

For current geodetic-type GPS receivers, the sampling rate is usually at least 1 sample per second $(1 \mathrm{~Hz})$, which is sufficient for most antenna heights in current GPS networks, however, not all networks store sampling rates as high as $1 \mathrm{~Hz}$ because of data storage limitations.

Regarding resolution and quality of the SNR observations, there is a considerable inconsistency among receiver manufacturers and models, see e.g., Bilich et al. (2007). However, looking at previous studies of SNR affected by multipath from the ocean, the SNR resolution needs to be on the order of $1 \mathrm{~dB}$ in order to resolve the SNR oscillations (Anderson, 2000; Löfgren et al., 2011a; Larson et al., 2013a).

Considering the above mentioned conditions and considering that there needs to be a co-located traditional tide gauge for validation, there are multiple GPS stations world wide. In order to create a dataset with stations in different locations and with different surroundings, the following parameters where of interest: different latitudes ensuring different satellite geometries, different surroundings (open sea water in several directions to antennas in harbors), different tidal ranges, and different tidal components (sea level driven by tides and sea level driven by meteorological forcing). The following GPS sites where chosen for this study: GTGU (Onsala, Sweden), SC02 (Friday Harbor, USA), BRST (Brest, France), BUR2 (Burnie, Australia), and OHI3 (O'Higgins, Antarctica), see Fig. 5 for images of the five different antennas.

\subsection{GTGU - Onsala, Sweden}

The GTGU station is located at the Onsala Space Observatory (OSO) on the west coast of Sweden $\left(57.4{ }^{\circ} \mathrm{N}, 11.9{ }^{\circ} \mathrm{E}\right)$. The antenna is part of a two-antenna experimental installation, with one zenith and one nadir-looking antenna, for measuring sea level (see Fig. 5a). For this study only data from the zenithlooking antenna, a Leica AR25 multi-GNSS choke-ring, was used. This antenna is covered by a hemispherical radome and is connected to a Leica GRX1200GGPRO GNSS receiver recording data with $1 \mathrm{~Hz}$ sampling rate. SNR data for GPS $\mathrm{L}_{1}$ were collected during six months from November 4 (doy 308), 2011, to May 7 (doy 128), 2012. The resolution of the recorded SNR data was $0.25 \mathrm{~dB}-\mathrm{Hz}$.

The location of the installation provides open sea water in a southward direction. To the east, the extent of the water surface is limited by bedrock and to the west the water surface is limited by a few smaller islands. The mean vertical position of the antenna was approximately $3 \mathrm{~m}$ above the sea surface.

During the time of the study, there were no traditional tide gauges installed at OSO. The closesed tide gauges were two stilling well gauges, operated by the Swedish Meteorological and Hydrolocial Institute (SMHI), in Ringhals and Göteborg about $18 \mathrm{~km}$ south of and $33 \mathrm{~km}$ north of OSO, respectively. In the end of September 2012 three pressure sensors for measuring sea level where installed next to GTGU. In order to compare the GPS sea level to a single tide gauge time series that was representative for Onsala, the pressure sensor sea level (mean of the three pressure sensors at each epoch) was fitted to the Ringhals and Göteborg sea level for dates September 29 (doy 273) to December 31 (doy 366), 2012. The model consisted of a rate for each tide gauge time series and a common bias, see Löfgren (2014). The coefficients from the fit where then applied to the Ringhals and Göteborg sea level for the times of the GTGU data set to create a composite tide gauge sea level time series for Onsala. The temporal resolution of the composite sea level was from 5 to 10 minutes. 


\subsection{SCO2 - Friday Harbor, USA}

The University Navstar Consortium (UNAVCO) station SC02 is located in Friday Harbor, Washington, on the west coast of the USA $\left(48.5^{\circ} \mathrm{N}, 123.0^{\circ} \mathrm{W}\right)$. The installation consists of a Trimble TRM29659.00 choke-ring antenna, with a hemispherical radome, connected to a Trimble NETRS GPS receiver (UNAVCO, 2013), which is recording data with $1 \mathrm{~Hz}$ sampling rate. The antenna is located on bedrock with open sea water to the east and southeast, see Fig. 5b, and the mean vertical position of the antenna is approximately $5.5 \mathrm{~m}$ above the sea level. SNR data for GPS $L_{1}$ were collected during one year from January 1 (doy 1) to December 31 (doy 366), 2012. The resolution of the recorded SNR data was $0.10 \mathrm{~dB}-\mathrm{Hz}$.

The Friday Harbor tide gauge is operated by the National Oceanic and Atmospheric Administration (NOAA) and is located about $300 \mathrm{~m}$ west of the SC02 station. The tide gauge consists of an Aquatrak air acoustic sensor in a protective well (Ehret, 2013). Sea level observations with the temporal resolution of 6 min were collected for the year 2012 .

\subsection{BRST - Brest, France}

The Institut National de l'Information Geographique et Forestiere (IGN) station BRST is located in the harbor of Brest on the west coast of France $\left(48.4^{\circ} \mathrm{N}, 4.5^{\circ} \mathrm{W}\right)$. The installation consists of a Trimble TRM57971.00 choke-ring antenna, without radome, connected to a Trimble NETR9 GNSS receiver (Dow et al., 2009), which is recording data with a $1 \mathrm{~Hz}$ sampling rate. The antenna is installed on a pillar on the roof of an old fortress, the mean vertical position of the antenna is approximately $17 \mathrm{~m}$ above the sea surface, overlooking the inlet of the harbor to the south east, see Fig. 5c. SNR data for GPS $L_{1}$ were collected during one year from January 1 (doy 1) to December 31 (doy 366), 2012. The resolution of the recorded SNR data was $0.25 \mathrm{~dB}-\mathrm{Hz}$.

The Brest tide gauge is operated by Réseaux de référence des observations marégraphiques (REFMAR) and consists of a Krohne BM100 reflex-radar sensor (REFMAR, 2013). The tide gauge is located less than $500 \mathrm{~m}$ north of the BRST station. Sea level observations with the temporal resolution of $1 \mathrm{~min}$ were collected for the year 2012 .

\subsection{BUR2 - Burnie, Australia}

The Geoscience Australia station BUR2 is located in the harbor of Burnie in Tasmania, Australia $\left(41.0{ }^{\circ} \mathrm{S}, 145.9{ }^{\circ} \mathrm{E}\right)$. The installation consists of a Leica AT504 choke-ring antenna, with a hemispherical radome, connected to a Leica GRX1200GGPRO GNSS receiver (Geoscience Australia, 2013), which is recording data with $1 \mathrm{~Hz}$ sampling rate. The antenna is located on a harbor pier with open sea water to the southeast, see Fig. 5d, and the mean vertical position of the antenna is approximately $5.5 \mathrm{~m}$ above the sea level. SNR data for GPS $\mathrm{L}_{1}$ were collected during one year from January 1 (doy 1) to December 31 (doy 366), 2012. The resolution of the recorded SNR data was $0.25 \mathrm{~dB}-\mathrm{Hz}$.

The Burnie tide gauge is operated by the Bureau of Meteorology and consists of an Aquatrak NG XCR acoustic-in-air sensor (Bureau of Meteorology, 2013). The tide gauge is located just next to the BUR2 installation. Sea level observations with the temporal resolution of $1 \mathrm{~h}$ were collected for the year 2012.

\subsection{OHI3 - O'Higgins, Antarctica}

The station $\mathrm{OHI} 3$ is located at the Bundesamt für Kartographie und Geodäsie (BKG) research station at O'Higgins, Antarctica $\left(63.3{ }^{\circ} \mathrm{S}, 57.9{ }^{\circ} \mathrm{W}\right)$. The installation consists of a LEIAR25.R3 choke-ring antenna, with a hemispherical radome, connected to a Leica GRX1200+ GNSS receiver (changed from a Leica GRX1200GGPRO GNSS receiver on February 9, 2012) (Dow et al., 2009), which is recording data with $1 \mathrm{~Hz}$ sampling rate. The antenna is located on a pillar with oper sea water to the west and northwest, see Fig. 5e, and the mean vertical position of the antenna is approximately $11.0 \mathrm{~m}$ above the sea level. SNR data for GPS $\mathrm{L}_{1}$ were collected during one year from January 1 (doy 1) to December 31 (doy 366), 2012. The resolution of the recorded SNR data was $0.25 \mathrm{~dB}$ $\mathrm{Hz}$.

The O'Higgins tide gauge is operated by the BKG and consists of radar gauge mounted on a beam extending over the coast line. The tide gauge installation is located less than $100 \mathrm{~m}$ northeast of the OHI3 station. During the Antarctic winter the water under the radar gauge freezes, preventing measurements with the radar gauge (Kühmstedt, 2013). Furthermore, during this period there can be icebergs in the bay, which can damage the installation. Therefore, the tide gauge is only operated during the ice-free times of the year. The available data for this study consisted of observations from January 19 (doy 19) to April 17 (doy 108), 2012, with a temporal resolution that was higher than 1 sample per second.

\section{Data analysis}

In order to analyze the SNR data with the methods presented in Sec. 2, the record from each station was screened to find satellite observations affected by multipath from the ocean together with the corresponding satellite azimuth and elevation angles. Broadcast ephemerides were used to calculate the satellite angles at each station. The starting point of the screening was an inspection of the surroundings of each station; in particular in which directions signals reflected off the ocean surface can be received. Based on this information, azimuth and elevation masks were created for each station. As an example, observation directions (after applying the azimuth and elevation mask) with overlayed dSNR data, showing the multipath oscillations, for station SC02 are presented in Fig. 6, top. The observed data are from one day and after applying the azimuth and elevation mask, 58 arcs remained. Figure 6 (top) illustrates both the satellite tracks, i.e., in what directions the satellites are observed, and the oscillations of the SNR (or dSNR) data arcs, showing where the surrounding reflectors are located.

The station SC02 is installed in an area northeast of Friday Harbor with the closest water surface fairly isolated from boat traffic, see Fig. 5b. Additionally, the antenna is located close to 

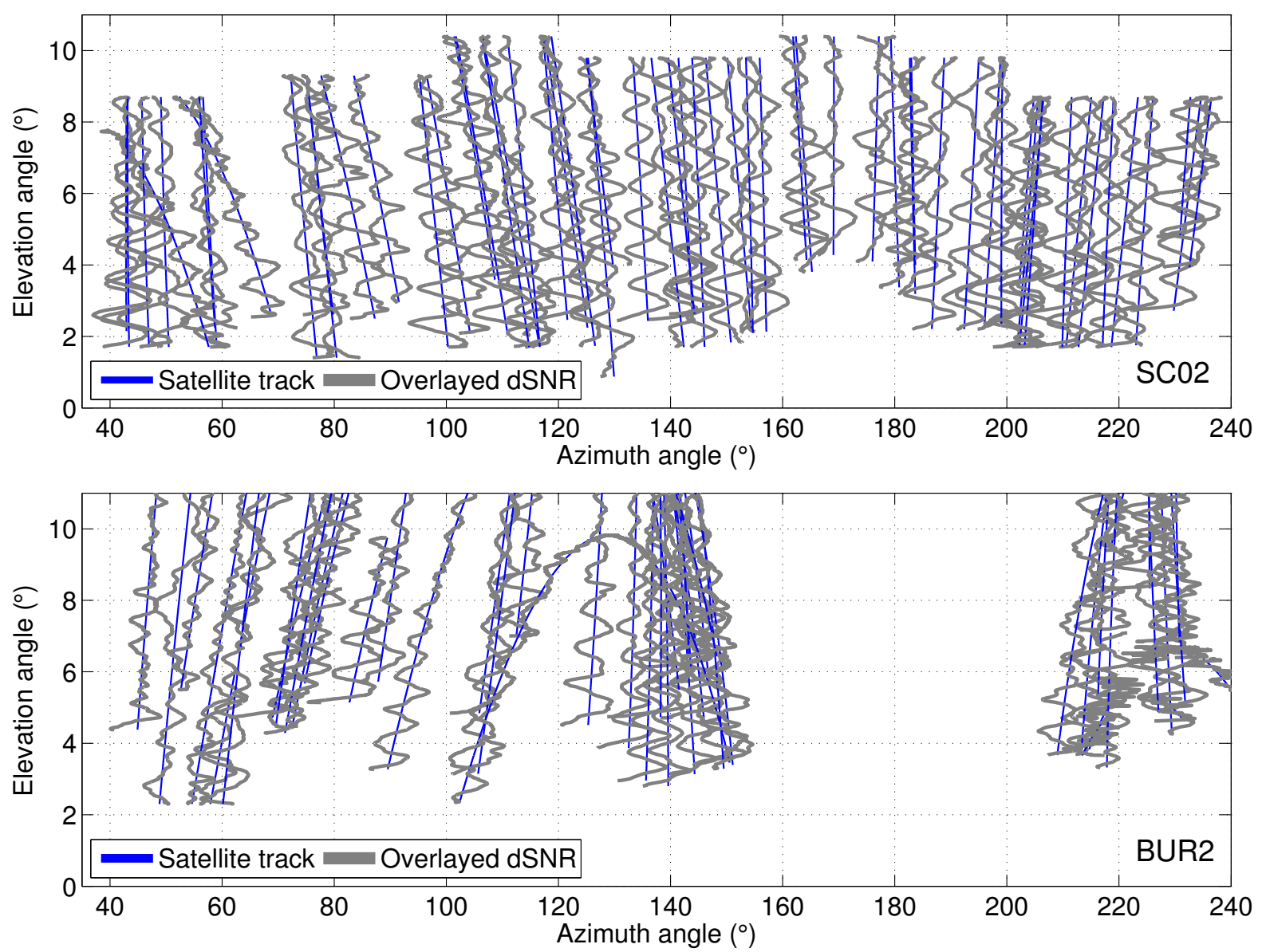

Figure 6: Azimuth and elevation angles of satellite observations, i.e., satellite track (blue lines), for one day for station SC02 (top), after applying the elevation and azimuth mask, and for station BUR2 (bottom), for the same elevation and azimuth range. Overlayed on the satellite tracks are the actual recorded data shown as detrended Signal-to-Noise Ratio (dSNR; gray lines). This means that the fluctuations in the dSNR corresponds to the elevation on the y-axis, but not to the azimuth angles on the $\mathrm{x}$-axis. However, with these figures it is possible to both illustrate the directions of the observations and assess in which directions the dSNR data are affected by multipath from single reflectors such as the sea surface. The dSNR observations for SC02 show from most azimuth angles a sinusoidal shape with a single multipath frequency. This is because of the open water in the east to southwest directions and the lack of other reflectors, see Fig. 5b. For BUR2, the dSNR observations from azimuth ranges of $40^{\circ}-120^{\circ}$ and $200^{\circ}-240^{\circ}$ show signs of multiple reflectors in those directions. However, the dSNR observations from the azimuth range of $120^{\circ}-160^{\circ}$ show clear sinusoidal shape and this range is therefore taken as the azimuth mask for BUR2.

the shoreline, and there are no islands or other reflectors in the water close to the antenna. This means that the azimuth mask can be wide, providing a large number of satellite observations. If the azimuth mask is correctly determined towards the ocean, the SNR observations should primarily be affected by multipath from the ocean. This can be seen in Fig. 6 (top), where the majority of the dSNR arcs, in the visible directions, show clear sinusoidal oscillations, having a single multipath frequency.

The station BUR2 is, in contrast to SC02, installed on a pier in the harbor of Burnie, see Fig. 5d. This means that the azimuth mask needs to be narrow, limiting the number of satellite observations, and even within the mask there can occasionally be other reflectors than the ocean surface, e.g., other piers and boats. As an example of the multipath environment of BUR2,
Fig. 6 (bottom) illustrates the same azimuth and elevation angles as for the SC02 mask in Fig. 6 (top) for one day. For the azimuth ranges of $40^{\circ}-120^{\circ}$ and $200^{\circ}-240^{\circ}$ in Fig. 6 (bottom), the dSNR arcs do not show clear sinusoidal oscillations or show several superimposed oscillations. This indicates that in these directions there are reflections from multiple reflectors and the data from these directions are therefore not suitable for the SNR-analysis. However, most of the dSNR arcs in the azimuth angles of $120^{\circ}$ to $160^{\circ}$ in Fig. 6 (bottom), show a clear sinusoidal shape with a single multipath frequency and therefore data from these azimuth angles are chosen for analysis. Nonetheless, a few of the observations in this azimuth range experience a superimposed second and perhaps third multipath frequency. 
A note should also be made about the reflective surface of each observation, which will move with the moving satellite. The reflective surface can be approximated by the first Fresnel zone and this has been described in several earlier studies related SNR-analysis, e.g., Larson et al. (2009); Löfgren et al. (2011b); Larson et al. (2013a). To summarize, the reflective surface is elliptic with the major axis in the direction towards the satellite and depends on the height of the antenna over the sea surface (a large distance to the sea surface corresponds to a large reflective surface and vice versa) and the satellite elevation angle (a small elevation angle corresponds to a large reflective surface). This means that an installation high over the sea surface will measure a larger surface than an installation which is closer to the sea surface.

After applying the azimuth and elevation masks to the data of each station, the SNR data, which are typically reported as carrier-to-noise-density ratio $C / N_{0}$ (Joseph, 2010), were converted from $\mathrm{dB}-\mathrm{Hz}$ in logarithmic scale to watt per watt in linear scale, assuming a $1 \mathrm{~Hz}$ bandwidth. For each satellite arc, a third order polynomial was fitted and removed, creating dSNR arcs. This was done in order to isolate the multipath contribution, see Sec. 2. To make sure that the multipath oscillations were not affected by the detrending, a dSNR arc with decreasing amplitude and oscillations corresponding to a reflector height of $2 \mathrm{~m}$ was simulated for sine of elevation angles of 0 to 0.26 (corresponding to elevation angles of $0^{\circ}$ to $15^{\circ}$ ). This elevation range is representable for 4 of the 5 stations in this study. Low-order polynomials of degree 0 to 8 were then fitted to the simulated dSNR arc and residuals were created from the difference between the simulated dSNR arc and the resulting polynomial from each fit. The results from spectral analysis of the residual arcs and the simulated dSNR arc showed no differences in reflector height for polynomials of degree 0 to 3 , whereas the difference were between $2-4 \mathrm{~cm}$ for the residual arcs of polynomials of degree 4 and over.

Each dSNR arc was then analyzed using LSP with an oversampling factor of 40. The output from the LSP, i.e., spectral power as a function of frequency (or scaled to reflector height), was then analyzed to find the highest spectral power and the respective frequency. In order for the algorithm to not pick out unrealistic reflector heights, the spectral power was analyzed in a window around an average frequency derived from the mean sea level at each station. This window was always at least 1.5 times wider in frequency than the actual sea level range for the site, which was taken from the tide gauge record. Another restriction for finding the right frequency was that the highest spectral power always had to be at least 2 times larger than the power of the mean spectral power in the window. When the requirements for the highest spectral power were fulfilled, the corresponding frequency was converted into reflector height and then into sea level height. The mean time of the satellite arc was stored as a time-tag for the observation.

Because of the large vertical distance between the sea surface and the antenna at the station BRST, see Sec. 3.3, and because of the large tides at the site, the dSNR arcs were devided into sub-arcs from sine of satellite elevation angle $0.05\left(2.9^{\circ}\right)$ to 0.65 $\left(40.5^{\circ}\right)$ in steps of 0.05 before the LSP analysis. This was pos-
Table 1: Summary of the processing parameters for the GPS data: limits for the azimuth $\left(0^{\circ}-360^{\circ}\right)$ and elevation $\left(0^{\circ}-90^{\circ}\right)$ mask, number of outliers removed, mean arc length, and mean number of observations per day for each station.

\begin{tabular}{lrrrrr}
\hline & GTGU & SC02 & BRST & BUR2 & OHI3 \\
\hline Azimuth start/end $\left({ }^{\circ}\right):$ & $120 / 260$ & $40 / 240$ & $130 / 270$ & $120 / 160$ & $180 / 30$ \\
Elevation min/max $\left({ }^{\circ}\right):$ & $1.0 / 14.5$ & $1.6 / 10.4$ & $2.8 / 40.0$ & $2.3 / 12.0$ & $0.5 / 13.0$ \\
Outliers removed $(\%):$ & 1.1 & 1.3 & 2.9 & 3.4 & 4.0 \\
Mean arc length (min): & 30.8 & 20.6 & 7.4 & 25.8 & 14.5 \\
Mean obs. per day (nr): & 49 & 56 & $210^{*}$ & 14 & 71 \\
\hline
\end{tabular}

Every sub-arc (or sea level solution) is counted as an observations.

sible since the large reflector heights corresponds to high multipath frequencies, see Sec. 2. The resulting mean arc length of the dSNR for BRST was $7.4 \mathrm{~min}$, whereas for the other station it was between $14.5 \mathrm{~min}$ and $30.8 \mathrm{~min}$, see Tab. 1. Furthermore, it was possible to find multipath oscillations in the BRST data for elevation up to $40^{\circ}$, whereas for the other stations the clear oscillations were only on elevation of up to $14.5^{\circ}$. This could be an effect from the horizontal position of the antenna, which is located on the shoreline, and the large distance between the antenna and the ocean surface.

As described in Sec. 2, the assumption for the LSP analysis is that the reflector height is not time dependent. Since this model is not sufficient for sites with high tidal variations, the heightrate correction for each observation was also calculated. As a first attempt, the LSP aquired reflector heights from GPS were used to calculate the height-rates (time derivative of the reflector heights) that are for the corrections. However, this was not successful, since the height-rate values were too noisy. Instead, sinusoidal functions were fitted to the reflector height series for each day, estimated assuming a constant sea level during the SNR observations. The idea was that during one day, the most significant contribution to the changes in sea level comes from the diurnal and semi-diurnal tides with known frequencies, if the site does not experience a strong meteorological forcing. In order to reduce the number of parameters of the daily fit, only the mean frequencies of the dominant tides in each band, diurnal $\left(\mathrm{O}_{1}: 25.8 \mathrm{~h}, \mathrm{~K}_{1}: 23.9 \mathrm{~h}\right)$ and semi-diurnal tides $\left(\mathrm{M}_{2}: 12.4 \mathrm{~h}\right.$, $\mathrm{S}_{2}: 12.0 \mathrm{~h}$ ) were used. This resulted in diurnal and semi-diurnal frequencies with the period $24.9 \mathrm{~h}$ and $12.2 \mathrm{~h}$, respectively. From the daily sinusoidal fit, height-rates were calculated from the tangent of the function with 2 minutes of data around the time-tag of the estimated reflector heights. These height-rates were then used to correct the LSP derived sea level. This means that for each GPS station there is one time series from only LSP analysis (assuming that the reflector height is not time dependent) and one time series from LSP analysis, but with applied corrections (assuming a time dependent reflector height).

For station SC02, the sea level solutions for doy 200 and 201 (2012) were distorted and offset by several meters (compared to the other days of the year when the time series show clear diurnal and semi-diurnal tides) and they were therefore regarded 
as outliers and removed. The reason for the erroneous values was a different multipath environment during these two days, possibly from station maintenance.

In order to remove outliers, a mean filter with window size 5 (5 time steps) was applied on all GPS time series (both with and without correction). If an observation was outside of $3 \sigma$ in the difference between the original time series and the mean filtered time series, it was considered an outlier and removed. For all time series, less than $4.0 \%$ of the points were removed, see Tab. 1.

The tide gauge record from stations Friday Harbor and Burnie were used in the same form as downloaded, and the composite time series for Onsala has been described in Sec. 3.1. For the sea level time series measured at Brest, there was a time shift for the last 6 days of 2012; the data from these days were therefore discarded. The shorter time series from the radar gauge at O'Higgins experienced some periods of strong storms resulting in unreliable sea level values due movement of the mounting (Kühmstedt, 2012). These data sections were removed interactively.

\section{Sea level results}

The GPS-derived sea level was compared to independent sea level observations from co-located tide gauges (except for station GTGU where a composite tide gauge sea level was calculated), see Sec. 3. Because of the co-location of the GPS stations and the tide gauges, there was no need to compare absolute sea level, i.e., sea level with respect to the ITRF. Still, if absolute sea level is desired, determining the position of the GPS antenna is straightforward.

The GPS-derived sea level time series are relative to the antenna phase centre, whereas the tide gauge sea level observations are relative to the tide gauge benchmark. In order to compare the variations in sea level, a mean was removed from each time series. For the ease of viewing, the 1 year long time series for each station (6 months for GTGU) are not displayed here. Instead, a 7-day subset of the sea level time series is shown for each station, illustrating the daily variations in sea level. The GPS-derived sea level and the tide gauge sea level observations for Onsala (GTGU), Friday Harbor (SC02), Brest (BRST), Burnie (BUR2), and O'Higgins (OHI3) are shown in Fig. 7a, Fig. 7b, Fig. 7c, Fig. 7d, and Fig. 7e, respectively. Both the GPS solutions assuming a constant reflector height, here named LSP, and the GPS solutions assuming a time dependent reflector height, here named LSP+corr, are presented.

From the 7-day time series, it is clear that the GPS-derived sea level has a high correlation with the tide gauge sea level at all locations. The two GPS-derived sea level series follow the diurnal and semi-diurnal variations at Friday Harbor (Fig. 7b), Brest (Fig. 7c), Burnie (Fig. 7d), and O'Higgins (Fig. 7e), and they also follow the sea level variations at Onsala (Fig. 7a), a site where the meteorological forcing is much stronger than the tidal variations. It is not easy to visually see a difference between the two GPS solutions (LSP and LSP+correction) from the 7-day time series except for Brest, where it is clear that the corrected GPS sea level follow the tide gauge sea level better than the LSP only solution.

In order to directly compare the two GPS-derived sea level time series with the tide gauge sea level, the time tags of the tide gauge sea level were resampled to that of the two GPS time series. For stations SC02, BRST, and GTGU, the tide gauge sea level value with the closest time tag to each value in the GPS time series is chosen (given that the value is within 10 minutes of a GPS time tag). Because of the sparse sampling of the tide gauge at BUR2 (1 value per hour), the sea level series was interpolated (cubic interpolation) to the time tags of the GPS time series. For OHI3, where the radar gauge samples the sea level at more than 1 value per second, a two-minute mean was taken around the GPS time tags.

With the same time tags, the difference between the GPSderived sea level, using the two GPS solutions for each station, and the tide gauge sea level were investigated by histograms. As an example, histograms are shown for the site with the highest tidal range (Brest; see Fig. 8 left) and for the site with the lowest tidal range (Onsala; see Fig. 8 right). The histogram for BRST without the correction, see Fig. 8 left, has a wider distribution than the histogram with the correction. In addition, applying the correction makes the distibution of the difference in sea level more symetric. It is therefore again clear, that at a site with large tidal variations, the GPS-derived sea level with the correction agrees better with the tide gauge sea level than the GPS-derived sea level without the correction. However, at Onsala, where the sea level is driven primarily by meteorological forcing, the histograms with and without the correction, see Fig. 8 right, are visually indistinguishable. Histograms for the stations SC02, BUR2, and $\mathrm{OHI} 3$ are provided online as supplementary information to this paper.

As a complement to the histograms, Van de Casteele diagrams were created for the sites with the highest sea level ranges, i.e., BRST, SC02, and BUR2, see Fig. 9 right, middle, and left, respectively. The Van de Casteele diagram presents along the $y$-axis the sea level height measurements, and along the $\mathrm{x}$-axis the difference between sea level measurements of the tide gauge to be tested (here the GPS tide gauge) and the reference tide gauge (here the co-located traditional tide gauge), see e.g., Miguez et al. (2008). From the shape of the Van de Casteele diagrams it is possible to determine if systematic errors exist. For the site BRST and BUR2, the Van de Casteele diagrams are centred around zero difference, meaning no systematic errors, see Fig. 9 left and right. It also appears that there are more outliers on the negative side for site BRST. For the site SC02, see Fig. 9 middle, the Van de Casteele diagram is also centred around zero, but it seems as the diagram is slightly tilted, indicating a scale error. However, without additional measurements from other independent techniques at the site, it is not possible to determine the origin of the scale error. Van de Casteele diagrams for the stations OHI3 and GTGU can be found online as supplementary information to this paper.

The pairwise mean (absolute), maximum, and Root-MeanSquare (RMS) differences were calculated for the two GPS derived sea level solutions with respect to the tide gauge sea level. The results together with the number of points for the calcu- 

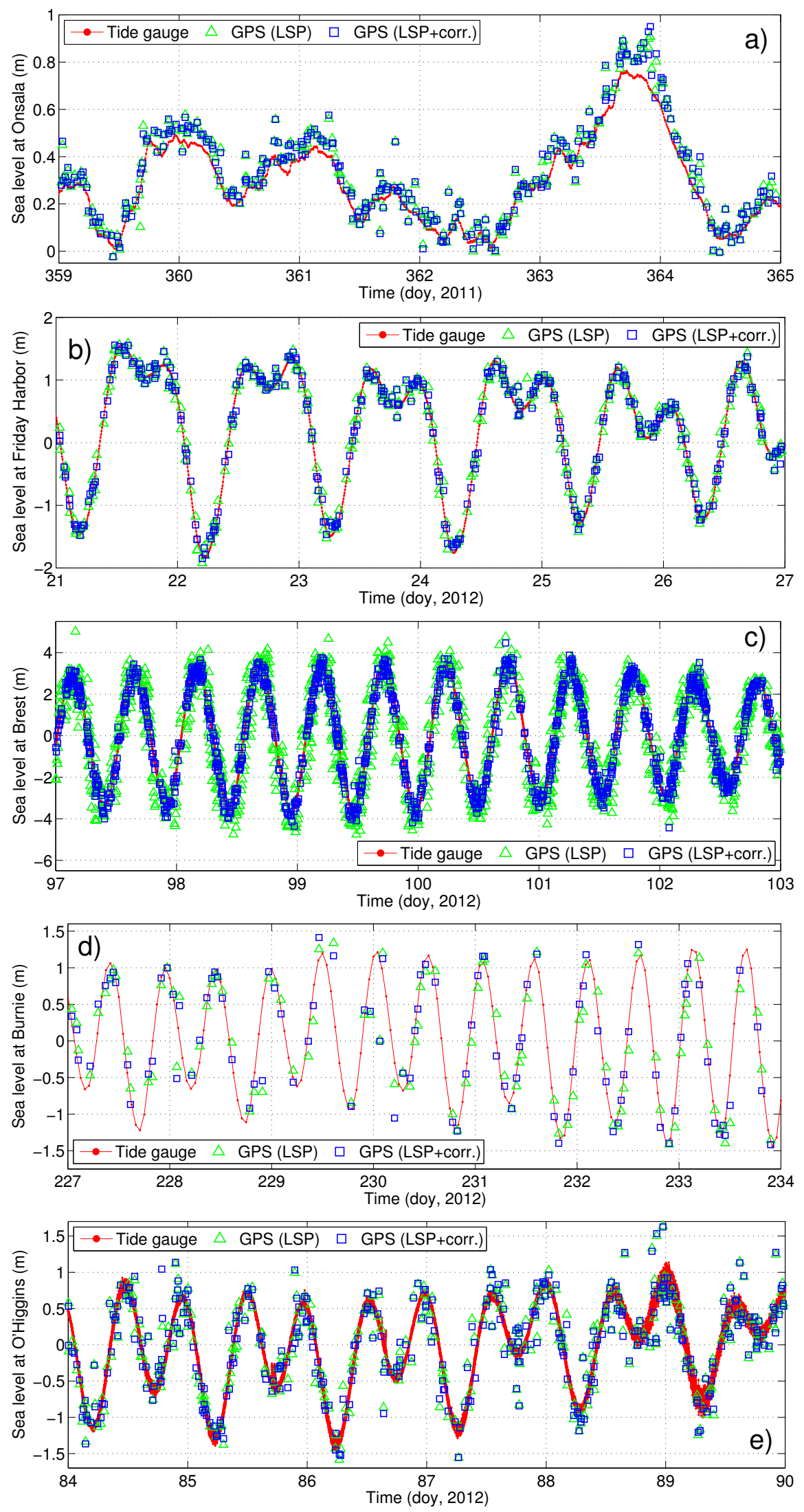

Figure 7: One week of sea level at Onsala (GTGU; a), Sweden, Friday Harbor (SC02; b), USA, Brest (BRST; c), France, Burnie (BUR2; d), Australia, and O'Higgins (OHI3; e), Antarctica, from the GPS Lomb Scargle Periodogram (LSP) solution, green triangles, the GPS LSP solution with a correction, blue squares, and the traditional co-located tide gauge, red lines with dots. 

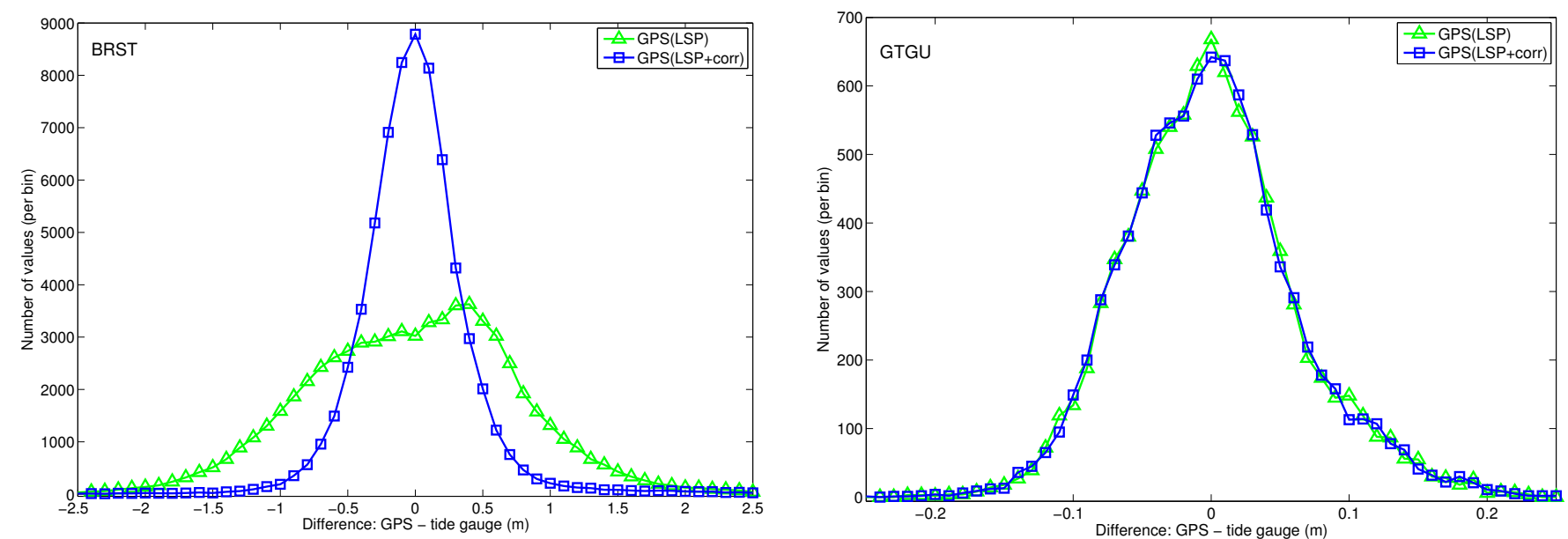

Figure 8: Histograms of the difference between the GPS-derived sea level using the Lomb Scargle Periodogram (LSP) solution, GPS(LSP) green triangles, and using the LSP solution and the correction, GPS(LSP+corr) blue squares, and the tide gauge sea level for station BRST (left) and GTGU (right). For a station with a large tidal range, such as BRST, applying the correction makes the distribution of the difference more narrow and symetric, i.e., the corrected GPS-derived sea level agrees better with the tide gauge sea level than the uncorrected. For a station with a low tidal range, such as GTGU, the result with and without the correction are visually indistinguishable, i.e., the agreement with respect to the tide gauge record is the same.
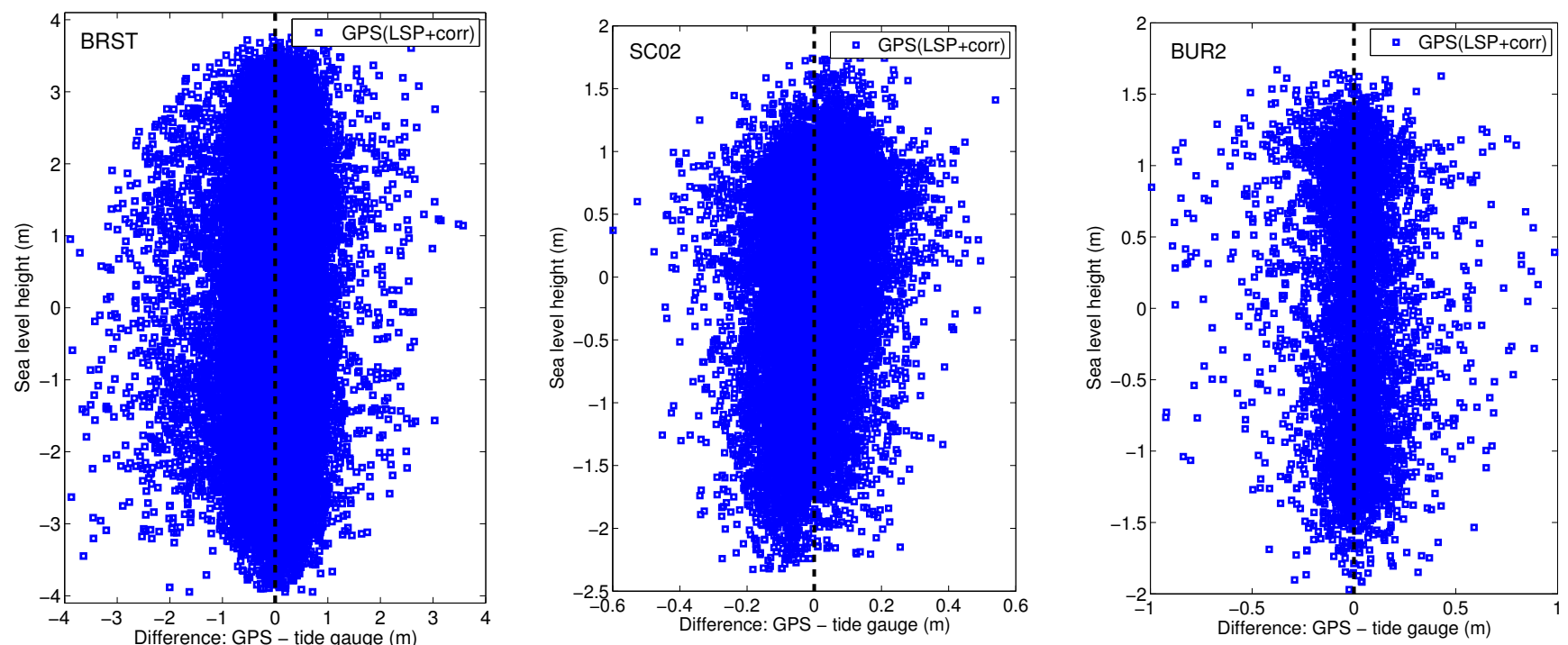

Figure 9: Van de Casteele diagrams for GPS-derived sea level from Brest (BRST; left), Friday Harbor (SC02; middle), and Burnie (BUR2; right). The Van de Casteele diagram presents along the $y$-axis the sea level height measurements, and along the $\mathrm{x}$-axis the difference between sea level measurements of the tide gauge to be tested (here the GPS tide gauge) and the reference tide gauge (here the co-located traditional tide gauge). The Van de Casteele diagrams for all sites are centred around zero difference, indicating no systematic errors. However, the diagram for the site $\mathrm{SC} 02$ appears to have a slight tilt, indicating a scale error. From the diagram, it is not possible to determine from which technique this error originates.

lation, correlation coefficients, and the tidal range (calculated from the tide gauge time series), are presented in Tab. 2.

From the high correlation coefficents ( 0.89 to 0.99$)$ in Tab. 2 , it is evident that the GPS-derived sea level gives valuable sea level results. RMS differences between the GPS-derived sea level and the tide gauge sea level are between $6.2 \mathrm{~cm}(6.2 \mathrm{~cm}$ with the correction) for GTGU with the lowest tidal range $(165.1 \mathrm{~cm})$ and $81.5 \mathrm{~cm}(43.2 \mathrm{~cm}$ with the correction) for BRST with the highest tidal range $(772.2 \mathrm{~cm})$. Although there seems to be a connection between increasing RMS and increasing tidal range, it is not fully evident in Tab. 2. As an estimation of the measurement relative accuracy, the RMS value divided by the tidal range give values of between $2.4 \%$ (3.0\% with the correction) for SC02 to $10.6 \%$ (5.6\% with the correction) for BRST.

When comparing the results for the two different GPS methods (LSP and LSP + correction, see Tab. 2) for a site with a 
Table 2: Summary of the comparison between the GPS-derived sea level, LSP and (LSP+)Corr, and the tide gauge sea level for the 5 stations. All RMS values, differences and ranges are given in centimetres.

\begin{tabular}{lcrrrrrrrrr}
\hline & \multicolumn{2}{c}{ GTGU } & \multicolumn{2}{c}{ SC02 } & \multicolumn{2}{c}{ BRST } & \multicolumn{2}{c}{ BUR2 } & \multicolumn{2}{c}{ OHI3 } \\
& LSP & Corr. & \multicolumn{1}{c}{ LSP } & Corr. & \multicolumn{1}{c}{ LSP } & Corr. & LSP & Corr. & LSP & Corr. \\
\hline Points (nr): & 8984 & 8989 & 20330 & 20315 & 67455 & 67151 & 4970 & 4974 & 5568 & 5567 \\
Corr. coeff.: & 0.97 & 0.97 & 0.99 & 0.99 & 0.89 & 0.97 & 0.95 & 0.96 & 0.89 & 0.89 \\
RMS: & 6.2 & 6.2 & 12.0 & 9.7 & 81.5 & 43.2 & 26.5 & 25.1 & 27.6 & 27.1 \\
Max. diff.: & 26.2 & 30.8 & 69.6 & 59.9 & 662.1 & 514.5 & 322.2 & 321.5 & 151.2 & 152.1 \\
Mean diff.: & 4.8 & 4.8 & 9.4 & 7.3 & 63.7 & 29.2 & 18.8 & 13.7 & 20.1 & 19.7 \\
Range: & 165.1 & 407.0 & & 772.2 & & 364.1 & 271.7 \\
Rel.Acc.*: & 3.8 & 3.8 & 3.0 & 2.4 & 10.6 & 5.6 & 7.3 & 6.9 & 10.2 & 10.0 \\
\hline
\end{tabular}

* $\quad$ Relative accuracy is calculated as RMS difference devided by the tidal range.

high tidal range, the GPS solution assuming a time dependent reflector height (or sea level) gives better agreement with the tide gauge records. For example at $\mathrm{SC} 02$ with a tidal range of $407.0 \mathrm{~cm}$ the RMS values are $12.0 \mathrm{~cm}$ and $9.7 \mathrm{~cm}$ for the LSP solution without and with the correction, respectively. This is consistent with what Larson et al. (2013b) reported. However, for a site with a small tidal variation, the results are the same both with and without the corrections, e.g., for GTGU with tidal range of $165.1 \mathrm{~cm}$ and the RMS value of $6.2 \mathrm{~cm}$. Thus, the correction term is more effective for stations with large tidal ranges.

The RMS value for the site GTGU was slightly higher in this study than in the study by Larson et al. (2013a); $6.2 \mathrm{~cm}$ compared to $4.8 \mathrm{~cm}$ respectively. The reason for this is most probably due to the longer data record used in this study, which was 6 months instead of 3 months, accounting for a more varying sea level. Other differences are that in this study, a new GPS installation was used and the results were compared with a colocated tide gauge, whereas in Larson et al. (2013a) the old GPS installation was used, same as in Löfgren et al. (2011b), and the results were compared to a synthetic tide gauge composed by the two nearest stilling well gauges.

\section{Tidal harmonic analysis}

In order to determine the amplitudes and phases of harmonic tide components, a least-squares fit of tides predicted with the harmonic development of Tamura (1987) was carried out. This stage includes pre-filtering in order to achieve a decorrelated noise contribution. For this purpose it is convenient to first project the time series on constant 12-second intervals (the closest bin catches the sample), and, in a second stage, resample it to 10 -minute intervals by linear interpolation. The 10 -minute sampling is motivated by the number of ordinates divided by the duration of the series, and by the luni-solar tidal frequency domain occupying much lower frequencies. The Nyquist period at 20 minutes still allows the determination of upper harmonics like $\mathrm{M}_{4}, \mathrm{M}_{6}$ etc.

The tide potential contains a rich spectrum of terms with narrow frequency spacing, much narrower than what could be resolved with observations limited to one year of duration. A one-year long batch of data allows, in principle, to discriminate tidal terms with an annual beat. However, the number of gaps in the series appears too large to expect the estimated tide parameters to decorrelate sufficiently. Hence, we have assumed that the data are worth less than $1 / 2$ years in terms of frequency resolution, and therefore combined tides with longer beat periods into wave groups. For instance, the wave groups of $S_{2}$ are combined with $K_{2}$, and $P_{1}$ is combined with $S_{1}$ and $K_{1}$. Since $\mathrm{K}_{2}$ is a small effect, and the tide generating potential is uniform with respect to frequency, the former combination is safe. In the diurnal case, the tide generating potential is influenced by the Nearly-Diurnal Free-Wobble (NDFW) of the earth core, so it contains a resonant term (see Wahr (1981) for the case of a spheriodal earth).

In the wave group formation, the amplitudes and phases of the tidal terms in the $\mathrm{P}_{1}-\mathrm{S}_{1}-\mathrm{K}_{1}$ group around have been modified in order to acquire the structure of the NDFW in the tidegenerating Love number expression $1-h_{2}+k_{2}$ (Wahr and Sasao, 1981).

The least-squares fit involves an outlier rejection scheme on the basis of a 5- $\sigma$ criterion, where $\sigma$ is the standard deviation of the residual. The rejection process is re-iterated until no ordinates exceed the limit. The data loss is typically on the order of $10 \%$ in both GPS data types.

The tidal harmonic analysis was performed with both GPSderived time series for each station. As a comparison, the harmonic analysis was also realized with the tide gauge records from all sites. The results of the tidal harmonic analysis for each station and sea level type are shown as semi-diurnal, diurnal, and long period tides in Tab. 3. From the table it is clear that station SC02, BRST, BUR2, and OHI3 all experi- 
Table 3: Harmonic solutions for the tide gauges sea level (TG), the GPS-derived sea level from LSP (LSP), and the GPS-derived sea level from LSP with the correction term (COR) at each of the 5 stations. Amplitudes (Amp) are given in millimetres and phases (Pha) are given in degrees. Amplitude uncertainties for the GPS-derived results for GTGU, SC02, and BUR2 are $\pm 2-4$ mm. The corresponding uncertainties for the tide gauge results are $\pm 2-11 \mathrm{~mm}$. The amplitude uncertainties for BRST are $\pm 11-36 \mathrm{~mm}$ and $\pm 5-31 \mathrm{~mm}$ for the GPS-derived and the tide gauge results, respectively. The corresponding amplitude uncertainties for OHI3 are $\pm 5-9 \mathrm{~mm}$ and $\pm 6-47 \mathrm{~mm}$, respectively.

\begin{tabular}{|c|c|c|c|c|c|c|c|c|c|c|c|}
\hline \multirow[t]{2}{*}{ Tide } & \multirow[t]{2}{*}{ Type } & \multicolumn{2}{|c|}{ GTGU } & \multicolumn{2}{|c|}{ SC02 } & \multicolumn{2}{|c|}{ BRST } & \multicolumn{2}{|c|}{ BUR2 } & \multicolumn{2}{|c|}{ OHI3* } \\
\hline & & Amp & Pha & Amp & Pha & Amp & Pha & Amp & Pha & Amp & Pha \\
\hline \multirow[t]{3}{*}{$\mathrm{S}_{2} \mathrm{~K}_{2}$} & TG & 7.9 & 79.1 & 133.6 & 35.8 & 754.8 & 148.1 & 147.1 & 186.2 & 299.6 & 336.9 \\
\hline & LSP & 10.6 & 97.8 & 121.0 & 35.9 & 734.1 & 145.9 & 124.3 & 193.9 & 278.0 & 335.8 \\
\hline & COR & 10.5 & 97.6 & 120.3 & 35.6 & 737.0 & 148.7 & 126.9 & 178.2 & 277.8 & 336.5 \\
\hline \multirow[t]{3}{*}{$\mathrm{M}_{2}$} & TG & 44.5 & 182.9 & 558.6 & 10.5 & 2048.8 & 109.0 & 1153.8 & 39.9 & 479.3 & 287.1 \\
\hline & LSP & 52.7 & 176.8 & 533.2 & 11.0 & 2004.8 & 106.6 & 990.3 & 50.5 & 453.2 & 287.3 \\
\hline & COR & 52.7 & 175.0 & 529.2 & 10.6 & 2002.4 & 108.9 & 1015.7 & 37.1 & 451.9 & 288.0 \\
\hline \multirow[t]{3}{*}{$\mathrm{N}_{2}$} & TG & 9.7 & 101.5 & 119.3 & 344.2 & 423.4 & 90.2 & 254.9 & 12.3 & 64.6 & 264.9 \\
\hline & LSP & 9.0 & 103.4 & 112.7 & 344.0 & 425.9 & 87.0 & 214.0 & 23.2 & 66.4 & 271.7 \\
\hline & COR & 8.9 & 104.3 & 112.2 & 343.9 & 417.9 & 90.3 & 219.3 & 10.1 & 66.7 & 270.9 \\
\hline \multirow[t]{3}{*}{$\mathrm{P}_{1} \mathrm{~K}_{1}$} & TG & 6.7 & 75.2 & 755.9 & 280.0 & 62.1 & 77.4 & 164.5 & 302.2 & 329.3 & 61.1 \\
\hline & LSP & 14.6 & 74.5 & 734.4 & 281.6 & 65.1 & 77.5 & 158.7 & 308.2 & 335.0 & 58.9 \\
\hline & COR & 14.5 & 73.6 & 733.9 & 281.2 & 64.5 & 76.7 & 155.6 & 303.0 & 333.2 & 59.5 \\
\hline \multirow[t]{3}{*}{$\mathrm{O}_{1}$} & TG & 22.4 & 288.9 & 431.8 & 258.7 & 68.3 & 330.2 & 118.3 & 274.3 & 363.2 & 46.6 \\
\hline & LSP & 21.7 & 282.3 & 415.2 & 258.5 & 61.1 & 299.5 & 76.6 & 294.2 & 350.5 & 46.6 \\
\hline & COR & 21.4 & 282.0 & 418.0 & 258.9 & 59.2 & 313.2 & 100.8 & 306.3 & 352.3 & 47.8 \\
\hline \multirow[t]{3}{*}{$\mathbf{M}_{f}$} & $\mathrm{TG}$ & 49.4 & 146.2 & 40.9 & 30.8 & 29.9 & 343.3 & 19.8 & 1.2 & 71.1 & 71.5 \\
\hline & LSP & 62.9 & 124.6 & 42.9 & 32.4 & 93.2 & 127.3 & 107.7 & 51.9 & 9.5 & 278.5 \\
\hline & COR & 61.9 & 125.5 & 40.4 & 38.1 & 31.0 & 31.2 & 97.3 & 33.3 & 2.7 & 140.2 \\
\hline \multirow[t]{3}{*}{$\mathrm{M}_{m}$} & TG & 74.6 & 304.0 & 22.6 & 337.0 & 23.2 & 326.6 & 15.6 & 18.6 & 22.7 & 29.7 \\
\hline & LSP & 77.4 & 306.8 & 22.0 & 334.3 & 36.0 & 285.5 & 13.6 & 32.6 & 15.3 & 118.6 \\
\hline & COR & 77.5 & 306.5 & 22.4 & 334.8 & 28.8 & 277.0 & 10.4 & 13.4 & 14.5 & 116.5 \\
\hline \multirow[t]{3}{*}{$\mathrm{S}_{s a}$} & $\mathrm{TG}$ & 134.5 & 101.2 & 20.6 & 284.0 & 110.6 & 298.2 & 6.0 & 294.7 & 233.5 & 57.3 \\
\hline & LSP & 171.6 & 96.9 & 18.9 & 291.7 & 45.5 & 338.9 & 29.7 & 285.0 & 21.1 & 136.4 \\
\hline & COR & 170.8 & 96.8 & 17.6 & 288.5 & 60.3 & 305.7 & 22.7 & 268.8 & 19.4 & 129.5 \\
\hline
\end{tabular}

* Tide gauge results from OHI3 are from analysis of three months of data.

ence strong semi-diurnal and diurnal tides, whereas the station GTGU experience strong long period tides. In general, there is a good agreement between the amplitudes and phases for the GPS-derived sea level and the tide gauge records. This holds true for stations with both large and small tidal range and can be seen in Fig. 10 (a-d), illustrating the most significant tides from left to right for GTGU, SC02, BRST, and BUR2. The results from $\mathrm{OHI} 3$ are left out of Fig. 10, since the tide gauge record from OHI3 only consisted of 3 months of data, which was deemed as too short for a meaningful comparison.

In Fig. 10, the uncertainties of the amplitudes are shown as error ellipses. These ellipses are throughout small, except for $\mathrm{S}_{s a}$ at BRST where all methods show a larger standard devi- ation. The better performance of the corrected GPS solution (assuming a time dependent sea level) for larger tidal ranges is observed also in the tidal analysis. It is easiest seen for the tidal components for BRST (Fig. 10abc), where the phase of the corrected GPS solution is closer to the tide gauge phase than the phase of the uncorrected GPS solution (assuming a static sea level). However, for GTGU, where the tidal range is smaller and the sea level is driven by meteorological forcing, both GPS methods perform in a similar manner. Additionally, for BUR2 where the observations are only from a narrow azimuth angle, both GPS methods show a similar agreement to the tide gauge. This shows that the method works well even with a restricted azimuth window. 
GTGU

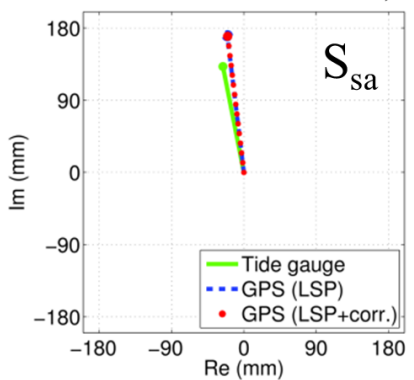

$\mathrm{SC} 02$

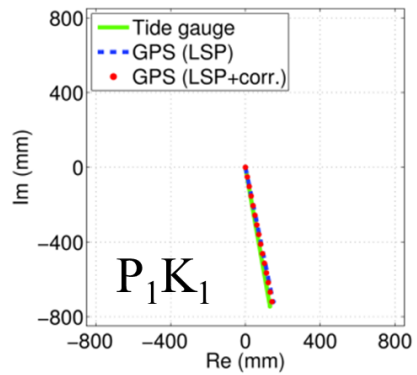

BRST

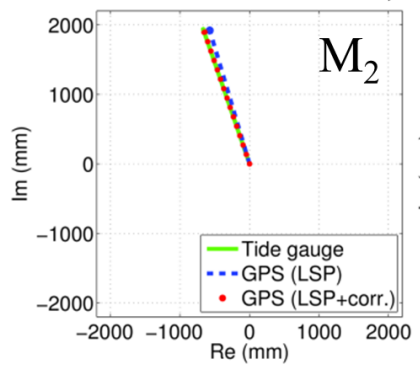

BUR2

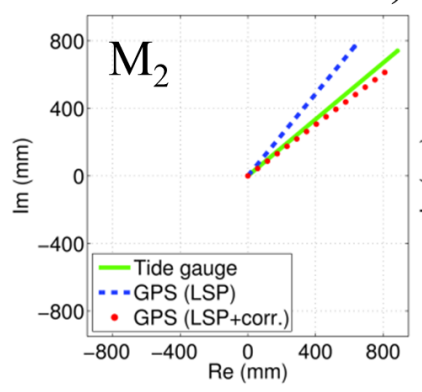

a2)

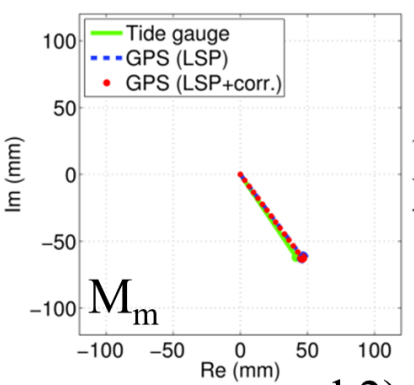

b2)

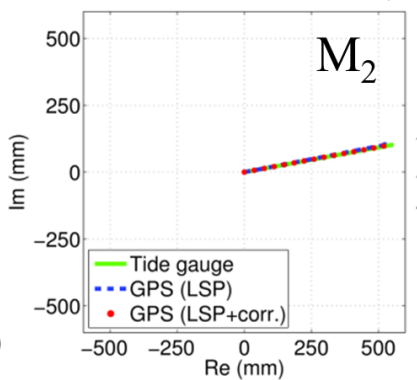

c2)

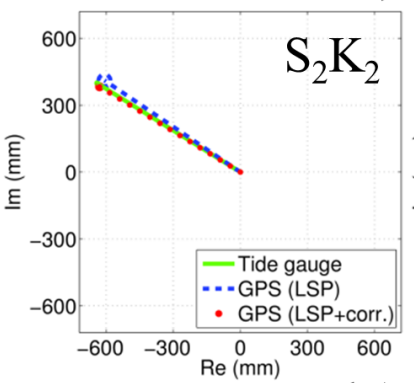

d2)

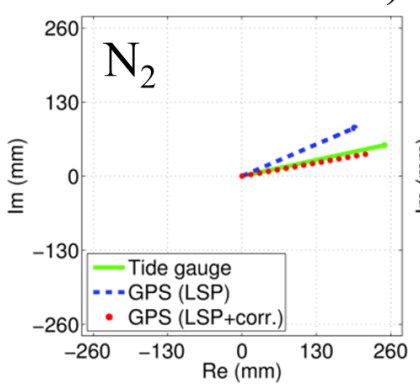

a3)

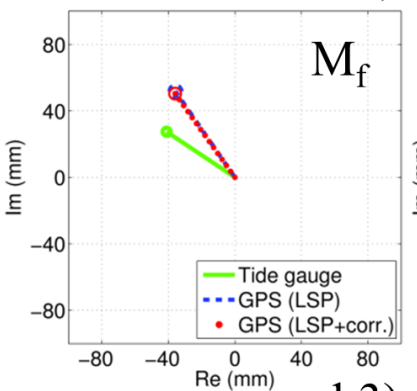

b3)

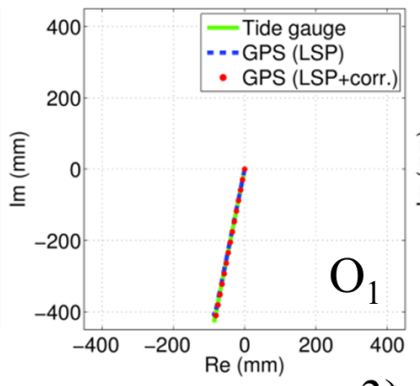

c3)

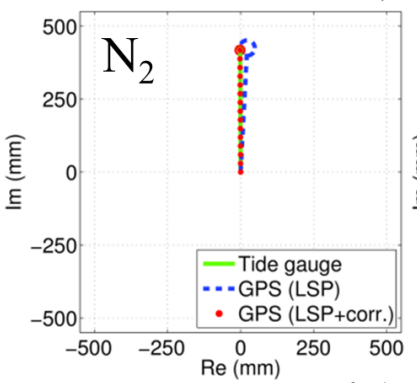

d3)

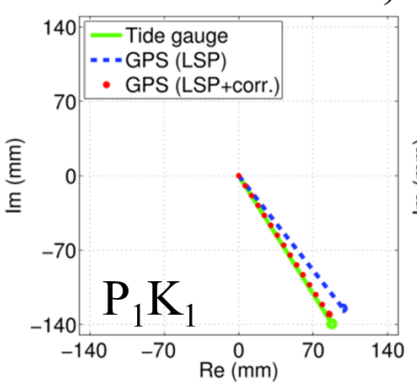

a4)

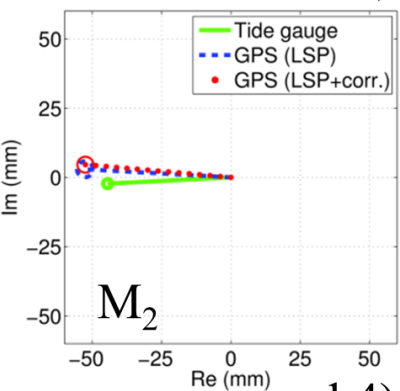

b4)

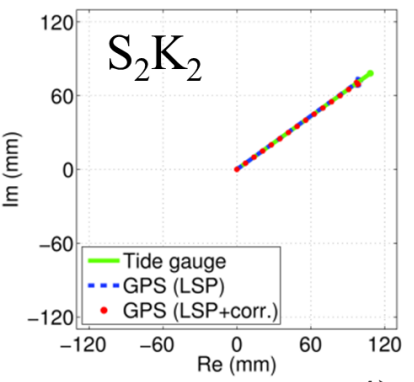

c4)

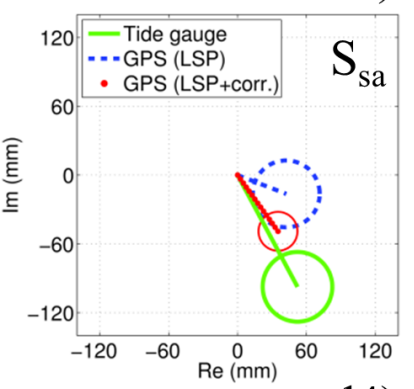

d4)

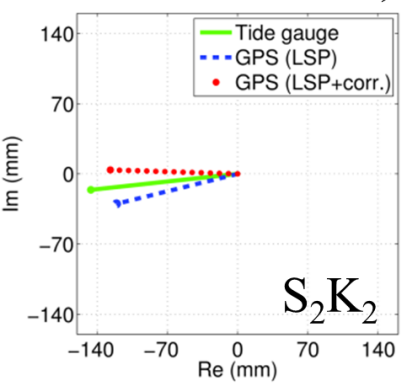

Figure 10: Amplitudes and phases of the 4 most significant tides (1-4) at the 4 stations (a-d) from the tide gauge, green line, the GPS sea level from LSP, blue dashed line, and the GPS sea level from LSP with the correction term, red dotted line. The most significant tide is displayed to the left, decreasing horizontally to the right. The uncertainties $(1 \sigma)$ of the amplitudes are shown as error ellipses.

As previously mentioned, no harmonic analysis was performed on the shorter tide gauge record at OHI3. However, analysis results were produced for the GPS-derived sea level, showing good agreement for semi-diurnal and diurnal tides, see Tab. 3.

The case of BUR2 offers some insights into non-tidal signal characteristics. After reducing the time series for tides and processing it through the whitening filter, we inspect the power spectrum of this residual series, see Fig. 11. We notice a spectral line pattern that does not die off with increasing frequency and interpret this as a sign for a persistent repeat pattern of a temporary spike. We suspect here a case for signal arrivals along multipath. BUR2 exhibits the problem more conspicuously than the other sites we have investigated. The strength 
of the pattern is primarily a consequence of the size of a multipath generating object. The clarity of the signatures depends on the number and attitudes of these objects, the more frequent they reflect signal into the antenna, the more the perturbations appear like an elevated noise floor. Common to all of these multipath events is their repeat cycle, the draconitic day of the GPS satellite system ( $245 \mathrm{~s}$ shorter than the solar day). When we resample the time series onto intervals that divide the draconitic day evenly and integer (we used 598.299 s), the perturbations from different days add constructively at the same draconitic time of each day, whereas other periods appear incoherent on this basis. The beat period of the solar day and the draconitic day of GPS, 352 solar days, is short enough to obtain acceptable SNR for multipath signal detection.

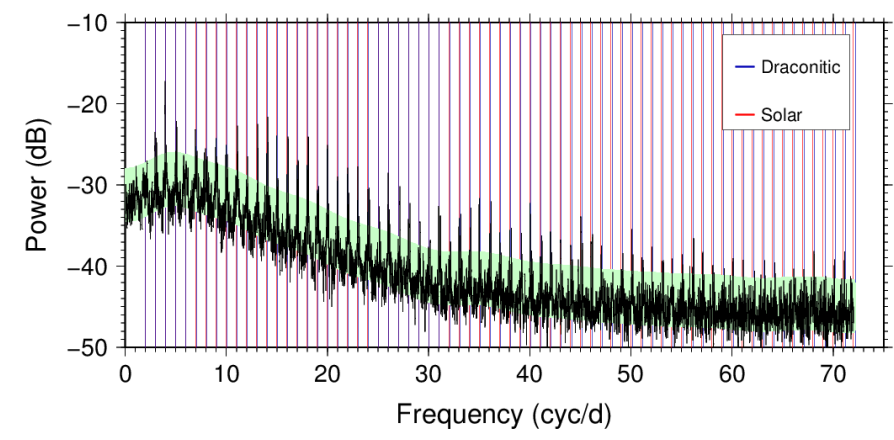

Figure 11: Power spectrum of the residuals after tidal analysis of the GPS-derived sea level, assuming a time dependent reflector height, for BUR2. The figure shows the residual signal after whitening using a maximum-entropy filter and reduction of tidal effects using a least-squares fit of the Tamura (1987) potential. The $95 \%$ confidence limit is shown in light-gray. The vertical lines mark multiples of the solar day and draconic day frequencies. The latter appear more often to coincide with signatures in the signal spectrum.

\section{Discussion}

The SNR analysis of one year of GPS data (6 months for GTGU) from the 5 different stations show a high agreement with the co-located tide gauges, see e.g., Tab. 2. The actual precision of the GPS results, as compared to the tide gauges, varies from site to site depending on the tidal range and also on the station location and multipath surroundings. For stations with high tidal range, the extended analysis model with a time dependent reflector height gives a better agreement with the tide gauge results than the simple analysis approach. For example, for the two stations with the highest tidal range in this study, BRST and SC02, the RMS agreement with respect to the tide gauge results improves from $81.5 \mathrm{~cm}$ to $43.2 \mathrm{~cm}$ and $12.0 \mathrm{~cm}$ to $9.7 \mathrm{~cm}$, respectively, when using the extended approach. However, for the station with the lowest tidal range in this study, GTGU, the extended model has no significant impact on the agreement with respect to the tide gauge results, except for the maximum difference that increases slightly for the extended analysis approach.
A plausible reason for this slight degradation is that the GTGU sea level is primarily affected by meteorological forcing, and thus the sinusoidal fit to derive the sea level height-rate is not appropriate for this station. The simple analysis approach appears to be applicable for stations with tidal range of up to about $270 \mathrm{~cm}$, where the extended approach gives only a small RMS improvement of $0.5 \mathrm{~cm}$.

The impact of sea surface roughness on the SNR-analysis results was investigated for all stations. Due to lack of sea surface roughness measurements, wind speed at $10 \mathrm{~m}$ height from European Centre for Medium-Range Weather Forecasts (ECMWF) was used as an indicator. No systematic dependences between wind speed and residuals, i.e., the difference between the GPS-derived sea level and the tide gauge records, were detected. Corresponding graphical material for the five stations is provided online as supplementary information to this paper. This finding is also confirmed in the more detailed study for the Onsala site, see Löfgren and Haas (2013).

The SNR-analysis was performed slightly different for the station BRST than for the other four stations. This is due to the large vertical distance between the BRST antenna and the sea surface (mean of approximately $17 \mathrm{~m}$ ). The large distance results in SNR oscillations with a much higher oscillation frequency than for the other stations and thus allows to divide the dSNR arcs into shorter sub-arcs, which increases the temporal resolution. Because of the large tidal range, the division into sub-arcs can also be seen as a necessary requirement. With a rapidly changing sea surface, the data from a full arc might be affected by both an increasing and a decreasing sea surface and hence cause problems for the analysis and produce weak results.

Another parameter that affects the final sea level result is the surrounding of a station. The ideal GPS station for this study would be a station located directly in the ocean, with water in all directions and no islands or boats, i.e., a station with only the sea surface as the multipath reflector. In reality, this is never the case, but with a reasonable azimuth and elevation mask, which is well defined from the surroundings, it is possible to come close to the ideal situation for some directions. As an example, one can compare the station $\mathrm{SC} 02$, which has a large open water surface to the east and southeast (Fig. 5c) to the station BUR2, which is in a harbor with a narrow mostly open water surface to the southeast. For SC02, which has a larger tidal range $(407.0 \mathrm{~cm})$, the RMS difference is comparably small ( $9.7 \mathrm{~cm}$ with the extended analysis approach). For BUR2, with a slightly smaller tidal range $(364.1 \mathrm{~cm})$, the RMS difference is substantially larger $(25.1 \mathrm{~cm}$ with the extended analysis approach) than for SC02. The reason for this lies most probably in different multipath surroundings, see Fig. 6a and Fig. 6b. Further investigations are necessary to improve the understanding of the non-tidal signals seen in the power spectrum of the residuals for BUR2 (see Fig. 11).

Despite being located in a harbor with multiple reflectors other than the ocean surface, BUR2 shows good agreement with the tide gauge record. This is seen both in the time domain, as high correlation of 0.96 , and for the harmonic analysis, where the amplitudes and phases for the semi-diurnal and diurnal tides 
are close to those of the tide gauge. For a station in an urban environment, like BUR2 (and also BRST), there is a trade-off between having a narrow azimuth mask, and thus limiting the effect from other multipath reflectors which can impact on the results, and the number of observations possible per day. For BUR2, the mean number of observations per day is 14, which is just about $30 \%$ of the number of observations for the other stations. However, the GPS-derived sea level at BUR2 shows good results, which indicates that it is possible to have a narrow azimuth mask and still derive meaningful sea level results. Of course there is a lower limit for the number of observations with which significant results can be achieved. Since many stations are close to harbors for infrastructural reasons, and thus limited in azimuth range, the additional use of other and multiple satellite systems, e.g., GLONASS, Galileo, and Beidou, appears favourable.

The tide gauge at O'Higgins can, because of the harsh environment, only be operated during parts of the year. During the Antarctic winter, the water under the radar gauge freezes, preventing measurements, and during periods of strong storms the measurements are unreliable because of the installation. However, sea level measurements from the reflected GPS signals have been produced for the whole year of 2012. Additionally, comparison of the 3 month common interval, the two sea level records show good agreement with correlation coefficients of 0.89 . This implies that the SNR technique can be used in places where it is impossible to use a traditional tide gauge. However, there is still an issue with the difference between GPS reflections from ocean and ice, but as can be seen in Fig. 7e, there is no doubt that the GPS-derived sea level resolves the tidal signals at O'Higgins.

All of the 5 stations in this study are equipped with chokering antennas, which are designed to reduce multipath reflections from low elevations. It is therefore of interest to investigate if the SNR-analysis method could be used with other antennas. Since this is not the scope of this study, the authors have provided an example of recorded SNR from a Leica AS10 antenna (connected to a GRX1200GGPRO) online as supplementary information to this paper, to illustrate the possibility of using this technique with other equipment. The SNR recorded by the AS10 antenna show similar multipath oscillations as those in the SNR recorded by the choke-ring antennas in this study, indicating that the same method can be applied for sea level determination. Furthermore, the example shows an SNR arc recorded with $1 \mathrm{~s}(1 \mathrm{~Hz})$ sampling and decimated to $30 \mathrm{~s}$ $(0.33 \mathrm{~Hz})$ sampling. In this particular case, the antenna was located 1-1.5 m over the sea surface, which was enough to sample each period of the SNR oscillations with more than 2 data points. As previously mentioned, the necessary sampling rate for each observation is dependent on the height of the antenna over the sea surface. In addition, it is a function of the rate of change of each satellite. With the data available for this study, a simple investigation of the possibility of using SNR data with 30 s sampling can be done for each site, i.e., decimating the SNR arcs to $30 \mathrm{~s}$ sampling and inspect if the remaining data points fulfil the Nyqvist theorem. Examples of decimated SNR arcs from the stations BRST and OHI3, the two stations which have the largest vertical distance to the sea surface (approximately $17 \mathrm{~m}$ and $11 \mathrm{~m}$, respectively), are provided online as supplementary information to this paper. From the decimated SNR arcs it should be possible to use data with 30 s sampling for station $\mathrm{OHI} 3$, but not for station BRST. Furthermore, the $1 \mathrm{~s}$ sampled data for the station BRST is more than enough to represent the SNR oscillations. This indicates that for $1 \mathrm{~s}$ sampled data, reflector heights of more than $17 \mathrm{~m}$ (actually more than $21 \mathrm{~m}$, accounting for the tidal range) are possible.

A final note on the SNR technique; the geodetic stations in this study are included in GNSS networks around the world operated by different organizations, which provide free-of-change data for research purposes. This means that the infrastructure for using GNSS data for sea level measurements around the world is already existing. In addition, data from these stations are continuously used to determine station positions and their movement with respect to the ITRF. Combining these position determinations with the GNSS derived sea level from the same station, results in absolute sea level with respect to the ITRF.

\section{Conclusions}

The SNR analysis of 1 year of data (6 months for GTGU) from 5 stations around the world has demonstrated the reliability of the GPS-derived sea level which was obtained from multipath signal analysis. The 5 different stations were selected because of their diversity: different locations mean different satellite geometry, different surroundings (provide different multipath evironments, e.g., open sea water or water surrounded by piers in a harbor), different tidal ranges (from $1.5 \mathrm{~m}$ to $7.5 \mathrm{~m}$ ), and different sea level variations (sea level driven by tides and sea level driven by meteorological forcing). Despite that the stations have essentially different locations, the GPS-derived sea level at all locations show high correlation of 0.89 to 0.99 with respect to sea level observed with co-located tide gauges.

The SNR analysis has been performed using two different approaches: a simple approach assuming a static sea level during a satellite arc, and an extended approach using a time dependent sea level during each satellite arc. For the latter, a priori knowledge of the time derivative of the sea level is necessary in order to calculate a correction term for the static solution. In this study, we applied a sinusoidal fit with the dominant semi-diurnal and diurnal tides to the static sea level estimates for each day to derive the height-rate correction term. For the sites with a large tidal variation the resulting corrected sea level records show smaller RMS values, when compared to the tide gauge records at the sites, than the uncorrected sea level records. However, at Onsala with a tidal range of $165 \mathrm{~cm}$, both analysis methods perform equally (RMS value of $6.2 \mathrm{~cm}$ ), except for the maximum difference where the corrected sea level performs worse $(30.8 \mathrm{~cm}$ compared to $26.2 \mathrm{~cm}$ for the uncorrected). This illustrates the difficulty in using our simple form of the extended analysis for stations where sea level is primarily driven by meteorological forcing. A further refinement of the extended analysis approach appears thus necessary. From the 5 stations with different tidal ranges $(165-772 \mathrm{~cm})$, the results indicate that the simple approach assuming a static sea level can 
be used for stations with a tidal range of up to about $270 \mathrm{~cm}$, without performing significantly worse than the extended analysis approach. The relative accuracy of the SNR-analysis, calculated as the ratio of the RMS difference and the tidal range, is between 2.4 and $10.0 \%$ for stations with low and high tidal range, respectively.

The harmonic tide analysis reveals that there is a good agreement between the amplitudes and phases for the GPS derived sea level and the tide gauge records for all sites. Again, the corrected GPS solutions based on the extended analysis approach perform better than the uncorrected ones for stations with a larger tidal range $(>2.7 \mathrm{~m})$. Furthermore, station SC02, BRST, BUR2, and OHI3 all experience strong semi-diurnal and diurnal tides, while the station GTGU experiences long period tides.

From our study we can conclude that the optimum station location to derive sea level from GPS data is somewhere rural with a wide and unobstructed view of the open ocean. This is of course not surprising, since this setting would mostly provide multipath signals from the ocean and not from other reflecting surfaces. A wide azimuthal view of the ocean allows for a higher number of observations per day than a narrower view. However, we have seen that even a station located in a harbor (BUR2), with a relative narrow azimuthal view and potentially multiple reflectors other than the ocean surface, can provide sea level results with good agreement to a co-located tide gauge (correlation coefficient 0.96, RMS difference $25.1 \mathrm{~cm}$ ).

In order to increase the temporal resolution without widening the observation mask, it should in the future be possible to use other GNSS, e.g., GLONASS, Galileo, and Beidou, and to perform multi-GNSS SNR-analysis.

\section{Acknowledgement}

The freely available GPS data used in this study: the GPS data from BRST and OHI3 are provided by the International GNSS Service (IGS; http://www.igs.org), the GPS data from BUR2 are provided by Geoscience Australia (http://www.ga.gov.au/), and the GPS data from SC02 are provided by University NAVSTAR Consortium (UNAVCO; http://www.unavco.org/). Furthermore, the tide gauge records were provided by the Swedish Meteorological and Hydrological Institute (SMHI; http://www.smhi.se/) for Göteborg and Ringhals in Sweden, the National Oceanic and Atmospheric Administration (NOAA; http://tidesandcurrents.noaa.gov/) for Friday Harbor in USA, the Réseaux de référence des observations marégraphiques (REFMAR; http://refmar.shom.fr/) for Brest in France, the Bureau of Meteorology (http://www.bom.gov.au/) for Burnie in Australia, and Elke Kühmstedt at Bundesamt für Kartographie und Geodäsie (BKG) for O'Higgins in Antarctica.

\section{References}

Anderson, K. D., 2000, Determination of Water Level and Tides Using Interferometric Observations of GPS Signals, J. Atmos. Oceanic Technol., vol. 17(8), pp. 1118-1127.
Bedford, L., Brown, N., Walford, J., 2009, Leica AR25 White paper, Leica Geosystems AG, Heerbrugg, Switzerland, 10 pp., available at http://www.leicageosystems.com/common/shared/downloads/inc/downloader.asp?id=10904 (Jan. 15, 2014).

Belmonte Rivas, M., Martin-Neira, M., 2006, Coherent GPS reflections from the sea surface, IEEE Geosci. Remote Sens. Lett., vol. 3, pp. 28-31.

Benton, C. J., Mitchell, C. N., 2011, Isolating the multipath component in GNSS signal-to-noise data and locating reflecting objects, Radio Sci, vol. 46, RS6002.

Bureau of Meteorology, 2013, Australian Baseline Sea Level Monitoring Project Hourly Sea Level and Meteorological Data, available at http://www.bom.gov.au/oceanography/projects/abslmp/data/ (Sept. 16, 2013).

Bilich, A., Axelrad, P., Larson, K. M., 2007, Scientific utility of the signalto-noise ratio (SNR) reported by geodetic GPS receivers, in proceedings of ION GNSS 2007, Institute of Navigation, Ft. Worth, TX, pp. 1999-2010.

Bilich, A., Larson, K. M., Axelrad, P., 2008, Modeling GPS phase multipath with SNR: Case study from the Salar de Uyuni, Boliva, J. Geophys. Res., vol. 113, B04401.

Bindoff, N. L., Willebrand, J., Artale, V., Cazenave, A., Gregory, J., Gulev, S., Hanawa, K., Le Qur, C., Levitus, S., Nojiri, Y., Shum, C. K., Talley, L. D., Unnikrishnan A., 2007, Observations: Oceanic Climate Change and Sea Level, In: Climate Change 2007: The Physical Science Basis. Contribution of Working Group I to the Fourth Assessment Report of the Intergovernmental Panel on Climate Change [Solomon, S., D. Qin, M. Manning, Z. Chen, M. Marquis, K. B. Averyt, M. Tignor and H. L. Miller (eds.)], Cambridge University Press, Cambridge, United Kingdom and New York, NY, USA, 385-432.

Caparrini, M., Egido, A., Soulat, F., Germain, O., Farres, E., Dunne, S., Ruffini, G., 2007, Oceanpal@: Monitoring Sea State with a GNSS-R Coastal Instrument, Proceedings of the 2007 IEEE International Geoscience and Remote Sensing Symposium, July 23-28 2007, Barcelona, Spain, pp. 5080-5083.

Chambers, D., Ries, J. C., Shum, C. K., et al., 1998, On the use of tide gauges to determine altimeter drift, J. Geophys. Res., vol. 103(C6), pp. 12885-12890.

Church, J. A., White, N. J., Konikow, L. F., Domingues, C. M., Cogley, J. G., Rignot, E., Gregory, J. M., van den Broeke, M. R., Monaghan, A. J., Velicogna, I., 2011, Revisiting the Earths sealevel and energy budgets from 1961 to 2008, Geophys. Res. Lett., vol. 38, L18601.

Dow, J. M., Neilan, R. E., Rizos, C., 2009, The International GNSS Service in a changing landscape of Global Navigation Satellite Systems, J. Geod., 83, pp. 191-198.

Ehret, T., 2013, Center for Operational Oceanographic Products and Services, Silver Spring, Maryland, USA, personal communication.

Elósegui, P., Davis, J. L., Jaldehag, R. T. K., Johansson, J. M., Niell, A. E., Shapiro, I. I., 1995, Geodesy using the Global Positioning System: The effects of signal scattering on estimates of site position, J. Geophys. Res., vol. 100, B6, pp. 2156-2202.

Georgiadou, Y., Kleusberg, A., 1988, On carrier signal multipath effects in relative GPS positioning, Manusc. Geod., 13, pp. 172-179.

Geoscience Australia, 2013, Global Navigation Satellite System Networks, available at http://www.ga.gov.au/earth-monitoring/geodesy/gnssnetworks.html (Sept. 16, 2013).

Hannah, B. M., 2001, Modelling and simulation of GPS multipath propagation, Ph.D. thesis, Queensland University of Technology.

Intergovernmental Oceanographic Commission (IOC) of UNESCO, 2006, Manual on Sea-level Measurements and Interpretation, Volume IV: An update to 2006, IOC Manuals and Guides No.14, vol. IV, JCOMM Technical Report No.31; WMO/TD. No.1339, 78 pp, Paris.

Joseph, A., 2010, What is the difference between SNR and C/NO?, InsideGNSS, 5(8), pp. 20-25.

Kühmstedt, E., 2012, Bundesamt für Kartographie und Geodäsie (BKG), Leipzig, Germany, personal communication.

Kühmstedt, E., 2013, Bundesamt für Kartographie und Geodäsie (BKG), Leipzig, Germany, personal communication.

Larson, K. M., Small, E. E., Gutmann, E. D., Bilich, A. L., Braun, J. J., Zavorotny, V. U., 2008, Use of GPS receivers as a soil moisture network for water cycle studies, Geophys. Res. Lett., vol. 35, L24405.

Larson, K. M., Gutmann, E. D., Zavorotny, V. U., Braun, J. J., Williams, M. W., Nievinski, F. G., 2009, Can we measure snow depth with GPS receivers?, Geophys. Res. Lett., vol 36, L17502. 
Larson, K. M., Löfgren, J. S., Haas, R., 2013a, Coastal sea level measurements using a single geodetic GPS receiver, Adv. Space Res., vol. 51, 8, pp. 13011310.

Larson, K. M., Ray, R. D., Nievinski, F. G., Freymueller, J. T., 2013b, The Accidental Tide Gauge: A GPS Reflection Case Study From Kachemak Bay, Alaska, IEEE Geosci. Remote Sens. Lett., vol. 10, 5, pp. 1200-1204.

Lidberg, M., Johansson, J. M., Scherneck, H-G., Milne, G. A., 2010, Recent results based on continuous GPS observations of the GIA process in Fennoscandia from BIFROST, J. Geod., vol. 50(1), pp. 8-18.

Löfgren, J. S., Haas, R., Johansson, J. M., 2011, Monitoring coastal sea level using reflected GNSS signals, J. Adv. Space Res., 47(2), pp. 213-220.

Löfgren, J. S., Haas, R., Scherneck, H.-G., Bos, M. S., 2011, Three months of local sea level derived from reflected GNSS signals, Radio Sci., vol. 46, RS0C05.

Löfgren, J. S. Haas, R., 2013, Sea level measurements using multi-frequency GPS and GLONASS observations, in review.

Löfgren, J. S., 2014, Local sea level observations using reflected GNSS signals, Ph.D. thesis, Department of Earth and Space Sciences, Chalmers University of Technology.

Martin-Neira, M., 1993, A PAssive Reflectometry and Interferometry System (PARIS): Application to ocean altimetry, ESA J., 17, pp. 331-355.

Martin-Neira, M., Colmenarejo, P., Ruffini, G., Serra, C., 2002, Altimetry precision of $1 \mathrm{~cm}$ over a pond using the wide-lane carrier phase of GPS reflected signals, Can. J. Rem. Sens., vol. 28(3), pp. 394-403.

Miguez, B. M., Testut, L., Wöppelmann, G., 2008, The van de casteele test revisited: an efficient approach to tide gauge error characterization, J. Atmos. Oceanic Technol., 25, pp. 1238-1244.

Mitchum, G. T., 1994, Comparison of Topex sea surface heights and tide gauge sea levels, J. Geophys. Res., vol. 99(C12), pp. 24541-24554.

Mitchum, G. T., 2000, An improved calibration of satellite altimetric heights using tide gauge sea levels with adjustment for land motion, Mar. Geodesy, vol. 23, pp. 145-166

Nievinski, F. G., 2013, Forward and inverse modeling of GPS multipath for snow monitoring, Ph.D. thesis, Department of Aerospace Engineering Sciences, University of Colorado.

Park, K.-D., Elósegui, P., Davis, J. L., Jarlemark, P. O. J., Corey, B. E., Niell, A. E., Normandeau, J. E., Meertens, C. E., Andreatta, V. A., 2004, Development of an antenna and multipath calibration system for Global Positioning System sites, Radio Sci., vol. 39, RS5002.

Réseaux de référence des observations marégraphiques (REFMAR), 2013, Marégraphe de Brest, available at http://refmar.shom.fr/brest (Sept. 16, 2013).

Scherneck, H.G., Lidberg, M., Haas, R., Johansson, J. M., Milne, G. A., 2010, Fennoscandian strain rates from BIFROST GPS: A gravitating, thickplate approach, J. Geodyn., vol. 50(1), pp. 19-26.

Schöne, T., Schön, N., Thaller, D., 2009, IGS Tide Gauge Benchmark Monitoring Pilot Project (TIGA): scientific benefits, J. Geod., vol. 83, pp. 249-261.

Tamura, Y., 1987, A harmonic development of the tide-generating potential, Bull. Inf. Maries Terr., 99, pp. 6813-6855.

University Navstar Consortium (UNAVCO), 2013, Geodetic GPS/GNSS Data, available at http://www.unavco.org/crosscutting/cc-data.html (Sept. 16, 2013).

Wahr, J. M., 1981, Body tides on an elliptical, rotating, elastic and oceanless earth, Geophys. J. R. astr. Soc., 64, pp. 677-703.

Wahr, J. M., Sasao, T., 1981, A diurnal resonance in the ocean tide and in the Earth's load response due to the resonant free core nutation, Geophys. J. R. astr. Soc., 64, pp. 747-765.

Wöppelmann, G., Letetrel, C., Santamaria, A., Bouin, M.-N., Collilieux, X., Altamimi, Z., Williams, S. D. P., Martin Miguez, B., 2009, Rates of sealevel change over the past century in a geocentric reference frame, Geophys. Re. Lett., vol. 36, L12607. 